\title{
The Toxicity Of Metallic Nanoparticles On Liver: The Subcellular Damages, Mechanisms, And Outcomes
}

This article was published in the following Dove Press journal: International Journal of Nanomedicine

\author{
Ying Yao* \\ Yiteng Zang* \\ Jing Qu \\ Meng Tang \\ Ting Zhang
}

Key Laboratory of Environmental Medicine and Engineering, Ministry of Education; School of Public Health, Southeast University, Nanjing 210009, People's Republic of China

*These authors contributed equally to this work
Correspondence: Ting Zhang Key Laboratory of Environmental Medicine and Engineering, Ministry of Education; School of Public Health, Southeast University, Nanjing 210009, People's Republic of China

Tel +86-25-83272566

Fax +86-25-83272566

Email zhangting@seu.edu.cn

\begin{abstract}
Metallic nanoparticles (MNPs) are new engineering materials with broad prospects for biomedical applications; thus, their biosafety has drawn great concern. The liver is the main detoxification organ of vertebrates. However, many issues concerning the interactions between MNPs and biological systems (cells and tissues) are unclear, particularly the toxic effects of MNPs on hepatocytes and other liver cells. Numerous researchers have shown that some MNPs can induce decreased cell survival rate, production of reactive oxygen species (ROS), mitochondrial damage, DNA strand breaks, and even autophagy, pyroptosis, apoptosis, or other forms of cell death. Our review focuses on the recent researches on the liver toxicity of MNPs and its mechanisms at cellular and subcellular levels to provide a scientific basis for the subsequent hepatotoxicity studies of MNPs.
\end{abstract}

Keywords: metallic nanoparticles, hepatotoxicity, subcellular injury, dysfunctions, toxicity outcome

\section{Introduction}

With the rapid development of nanotechnology, nanomaterials (NPs) are considered to have enormous application potential due to their unique properties over the past few decades. ${ }^{1}$ Of all the NPs, metallic nanoparticles (MNPs) have generated considerable commercial interest owing to unique properties of NPs such as small size and the greater surface area to volume ratio as well as different electronic, magnetic, optical, and mechanical properties and also particle shape. MNPs mainly include metal nanoparticles and metal oxide nanoparticles, and MNPs have been widely included in a great diversity of products and the various fields, such as electronic devices, cosmetics, paints, additives in food, and biological and medical systems. ${ }^{2,3}$ With the widespread application of MNPs, it is inevitable that MNPs will be released into the environment or contact with humans directly. Therefore, their potential risks to human health and the environment have gained even more attention. ${ }^{4}$ MNPs can enter the body in various ways, for example, through the inhalation, gastrointestinal tract, or skin, and circulate via the blood or lymphatic system, eventually accumulating in various organs. ${ }^{5}$ Previous studies for metal nanoparticles and metal oxides nanoparticles, including nano- $\mathrm{Cu}$, nano-Ag, nano-Ni, nano- $\mathrm{TiO}_{2}$, and nano- $\mathrm{ZnO}$, have shown that MNPs reached the lung and gastrointestinal tract through the respiratory and digestive tract, and further translocated to the systemic circulation, and then accumulate the potential target organs such as the liver and the mononuclear 
phagocytic system. ${ }^{6}$ As a secondary exposure site, the liver is extremely important, as it has been shown to accumulate MNPs at much higher quantities compared with other organs. ${ }^{7}$ Meanwhile, MNPs accumulate the liver typically results in interaction with hepatic cells and the possibility of changing the structure and function of hepatic cells. The liver is a complex network of inter-related cells, including about $60-80 \%$ of the hepatocytes, and the additional cells include Kupffer cells, liver sinusoidal endothelial cells, hepatic stellate cells, and so on. The interactions of MNPs with liver cells determine the fate of administered MNPs in vivo and the results of hepatotoxicity. In vivo studies are mostly focused on the accumulation of the MNPs at the organ level, while most in vitro studies are focused on hepatic cells and do not summarize changes in subcellular levels and their relationship with hepatotoxicity. It is important, therefore, to summarize hepatotoxicity studies of MNPs on animals, the cell level and subcellular level and its molecular mechanism and outcomes. Furthermore, the physicochemical characteristics of MNPs, such as size, surface properties, and chemical nature would change and influence their potential toxicity. From these facts, the aim of this review is to compile and discuss the hepatotoxicity effects of MNPs both in vitro and in vivo, particularly those involved in subcellular levels as well as to highlight its molecular mechanism of action of these MNPs.

\section{The Liver And Metallic Nanoparticles Toxicity}

The liver is the primary organ for detoxification in human body. It possesses abilities of deoxidation, glycogen storage, and secreted protein synthesis. It acts as biological barriers by isolating and eliminating various exogenous compounds through phagocytosis. Previous in vivo studies have shown that different types of MNPs: nano-metal monomers and nano-metal oxides, tend to deposit in the liver with extensive toxic effects. ${ }^{8-10}$ As shown in Table 1, MNPs entering the body cause changes in inflammatory cytokines. NiO NP increased the concentrations of proinflammatory cytokines (IL-1 $\beta$ and IL-6) but decreased the levels of anti-inflammatory cytokines (IL-4 and IL-10). ${ }^{11}$ Liver dysfunction caused by MNPs leads to structural changes of liver. MNPs caused inflammation, which may lead to changes in liver coefficients. ${ }^{12-14}$ By analyzing blood serum, significant decrease of total bilirubin and increase of alkaline phosphatase (ALP) with aspartate aminotransferase (AST) indicated liver injury. ${ }^{11,15,16}$ The damage mainly manifested in liver structural changes causing metabolic dysfunction. AgNP caused the increase of relative spleen weight and affected diffuse and severe hepatocyte necrosis and hemorrhage, as well as multifocal peribiliary microhemorrhages, occasional portal vein endothelial damage, which in turn affects the liver. ${ }^{17}$ $\mathrm{TiO}_{2} \mathrm{NP}$ induced alterations in the liver structure including hepatic inflammatory cell infiltration, increased density of liver tissue collagen, initiation of fibrosis and Glisson capsule thickness increase. ${ }^{18}$ AuNP was found to activate hepatic macrophages and then significantly aggravated the course of experimental immune hepatitis and liver injury. ${ }^{19}$

\section{The Hepatocytes And Metallic Nanoparticles Toxicity}

Hepatocytes constitute the basic functional unit of the liver, the hepatic lobule, which contains $60 \%$ of the solid cells (hepatocytes) and $30 \%$ to $35 \%$ of the non-solid cells (hepatic stellate cells, Kupffer cells, and sinusoidal endothelial cells). NPs deposited in liver tissue may affect the normal physiological and biochemical functions of liver by affecting liver parenchymal cells and other cells along with important physiological functions in liver tissue. When studying the hepatotoxicity of MNPs, the effects on hepatocytes from different sources, including primary cells and cell lines, should be considered at the same time, so as to obtain more comprehensive information. It has been widely carried out in vitro toxicity research of MNPs, including the use of cell lines from different species and origins, as well as studies at the cellular, subcellular and molecular levels.. MNPs cause liver cell toxicity mechanism includeing triggering inflammation, oxidative stress, and possibly eventually leading to different types of cell death outcomes. As shown in Table 2, due to the role of MNPs, the decrease in survival rate of hepatocytes is common, accompanied by a timeand dose-dependent relationship. The sensitivity of hepatocytes from different sources to MNPs was different. Compared with normal cell lines, MNPs seem to have more obvious toxic effects on cancer cells. In the study of Mei-Lang et al, ${ }^{22}$ the IC50 for SK-Hep-1 and HepG2 cells were 25 and $85 \mathrm{ug} / \mathrm{mL}$, respectively. Ali et al ${ }^{23}$ also found that HepG2 cells were more sensitive to rGO-Ag than human CHANG liver cells. The activity of lipid peroxide, superoxide dismutase, and catalase increased and glutathione decreased. Previous studies have shown 


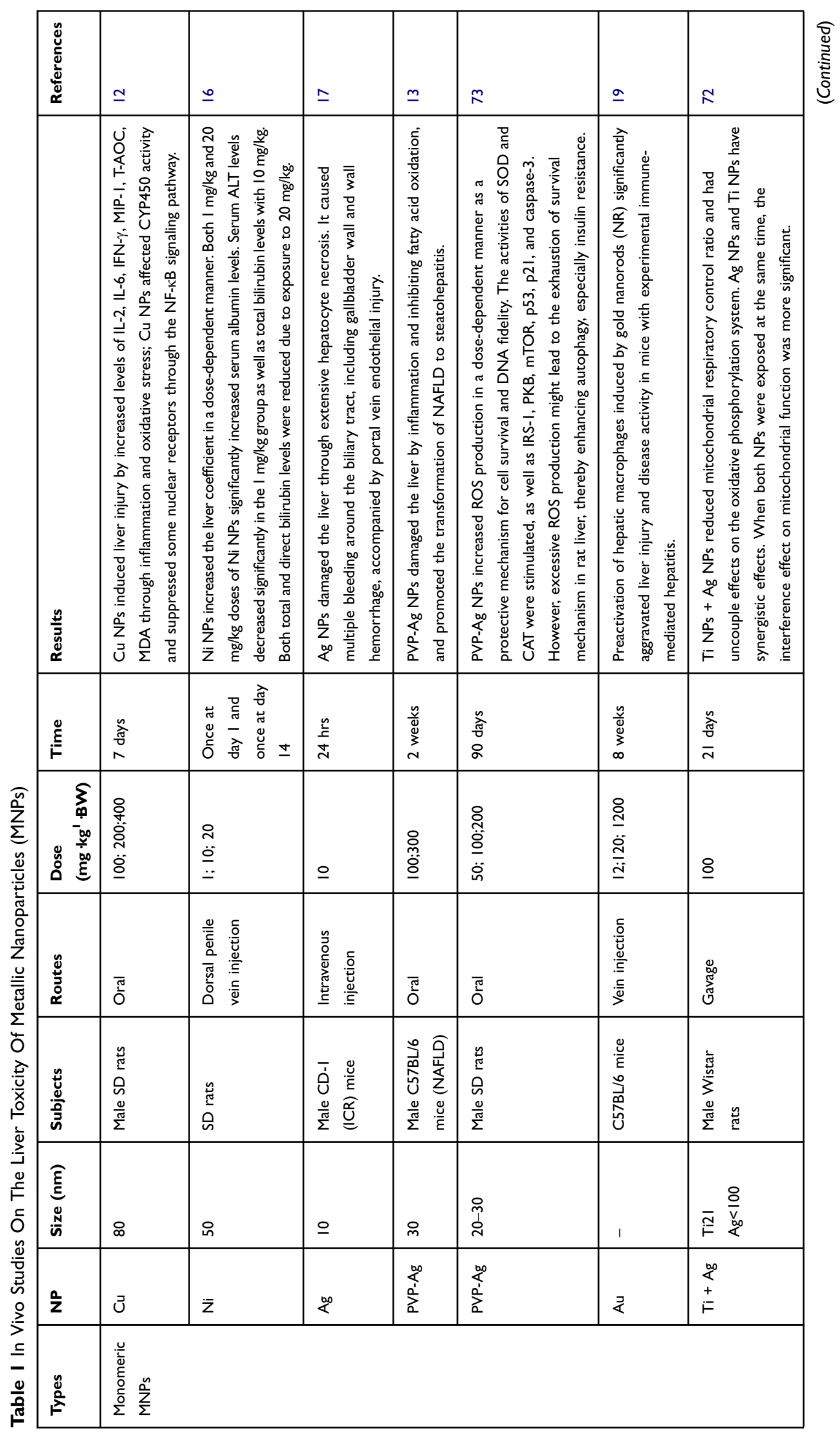




\begin{tabular}{|c|c|c|c|c|c|c|c|c|c|}
\hline జ & \pm & $\underline{\underline{n}}$ & $\underline{\infty}$ & $\stackrel{\circ}{m}$ & 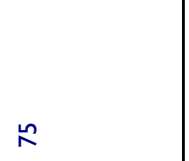 & 요 & $=$ & $\bar{N}$ & 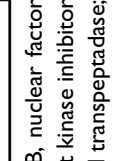 \\
\hline $\begin{array}{l}\frac{y}{\vec{z}} \\
\frac{\vec{y}}{x} \\
x\end{array}$ & 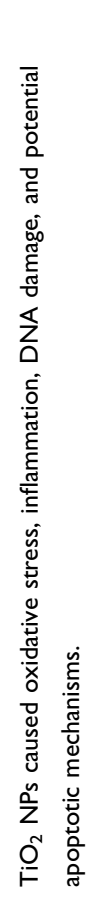 & 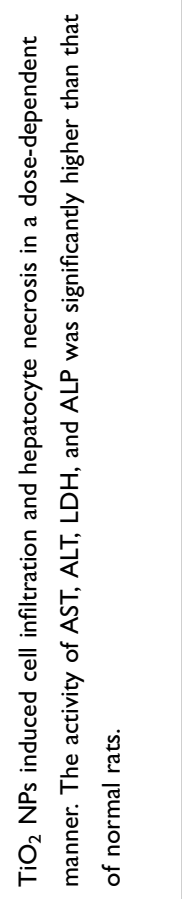 & 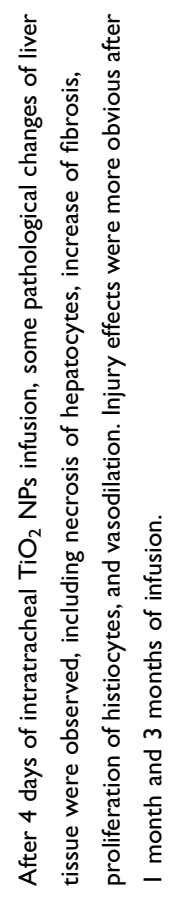 & 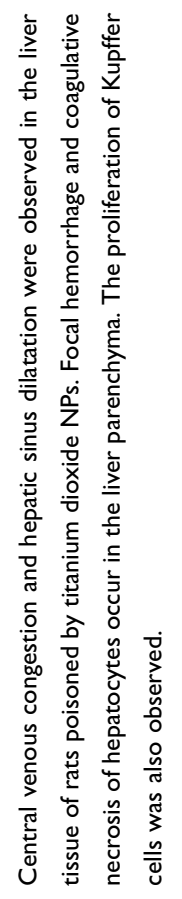 & 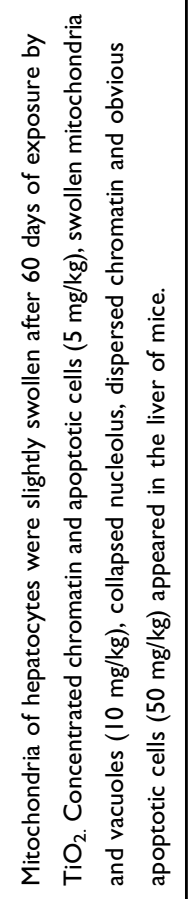 & 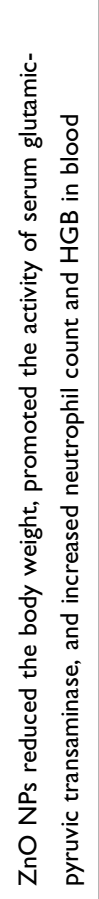 & 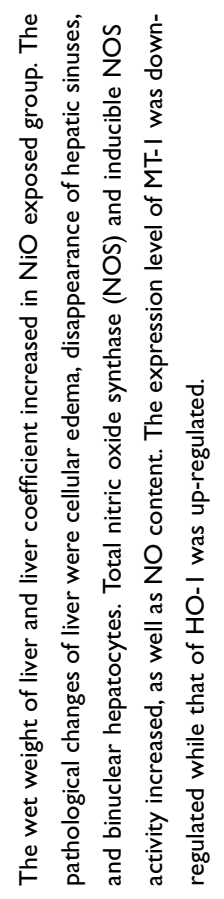 & 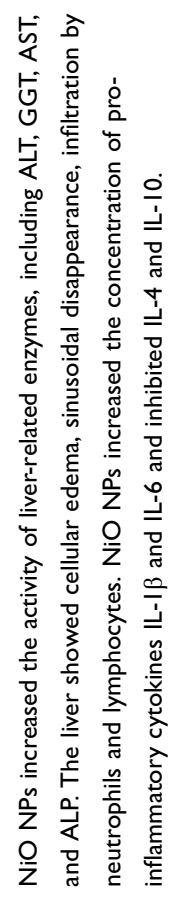 & 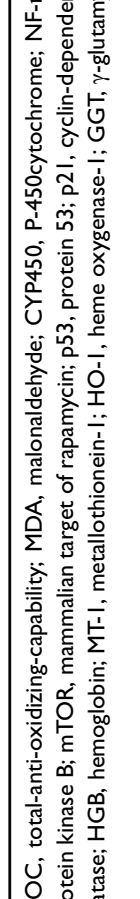 \\
\hline$\stackrel{\stackrel{\Xi}{\xi}}{\underline{\xi}}$ & 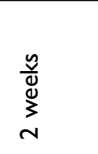 & $\begin{array}{l}\frac{n}{E} \\
\frac{N}{N}\end{array}$ & 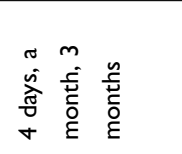 & $\begin{array}{l}\text { 命 } \\
\text { वे } \\
\text { t }\end{array}$ & $\begin{array}{l}\frac{n}{\hat{\jmath}} \\
0 \\
0 \\
0\end{array}$ & $\begin{array}{l}\frac{y}{0} \\
\frac{0}{0} \\
\end{array}$ & 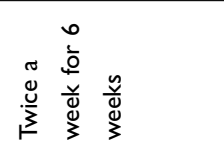 & 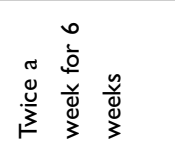 & 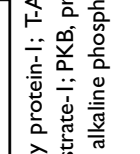 \\
\hline 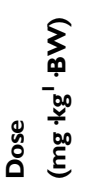 & 요 & & 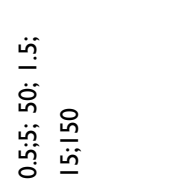 & 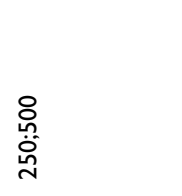 & 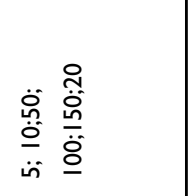 & ભํ & 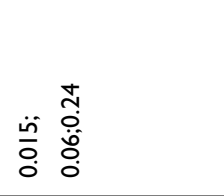 & 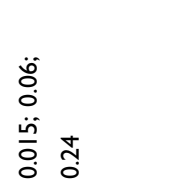 & 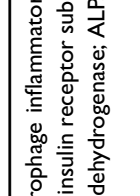 \\
\hline 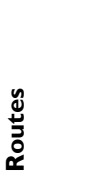 & $\overline{\overline{\widetilde{\sigma}}}$ & 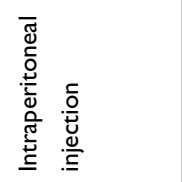 & 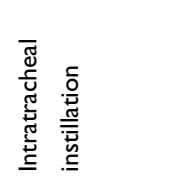 & $\overline{\overline{0}}$ & 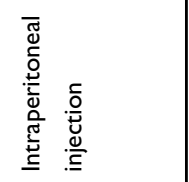 & $\overline{\overline{0}}$ & 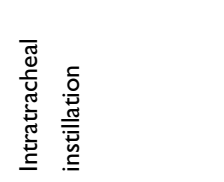 & 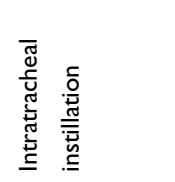 & 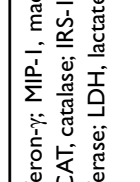 \\
\hline 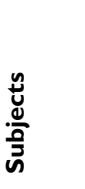 & 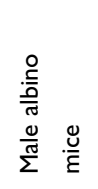 & 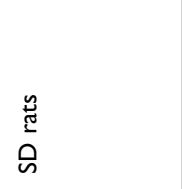 & 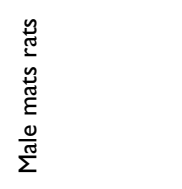 & 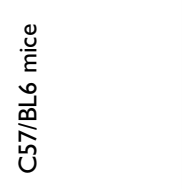 & $\begin{array}{l}\stackrel{\mathscr{U}}{\varepsilon} \\
\underline{\widetilde{U}}\end{array}$ & 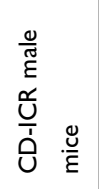 & 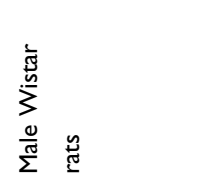 & 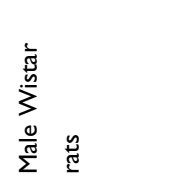 & \\
\hline 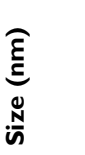 & $\bar{\sim}$ & 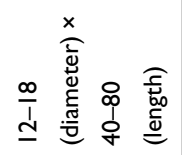 & $\bar{\sim}$ & $\bar{\sim}$ & 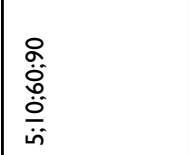 & q & 요 & 오 & \\
\hline$\frac{0}{z}$ & $\stackrel{\sim}{\stackrel{N}{F}}$ & $\stackrel{\sim}{\stackrel{N}{F}}$ & $\stackrel{\sim}{\stackrel{N}{F}}$ & $\stackrel{\sim}{\stackrel{N}{F}}$ & $\stackrel{\sim}{\stackrel{N}{F}}$ & O & $\frac{\mathrm{O}}{\mathrm{Z}}$ & $\frac{\mathrm{O}}{\mathrm{Z}}$ & \\
\hline ڤે & \multicolumn{9}{|c|}{ 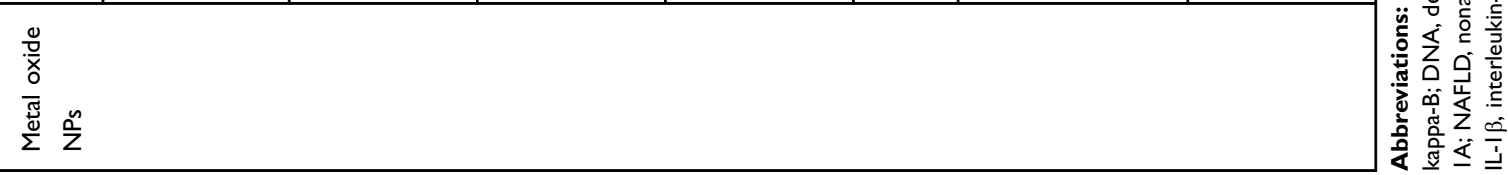 } \\
\hline
\end{tabular}




\begin{tabular}{|c|c|c|c|c|c|c|c|c|c|c|}
\hline 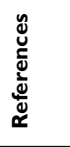 & in & n & $\tilde{m}$ & \multicolumn{2}{|l|}{$\stackrel{ \pm}{~}$} & $\stackrel{\sim}{\sim}$ & $\stackrel{\sim}{ }$ & ○ & $\approx$ & $\lambda$ \\
\hline 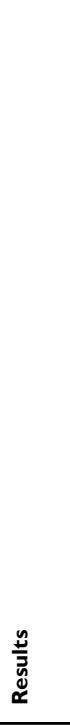 & 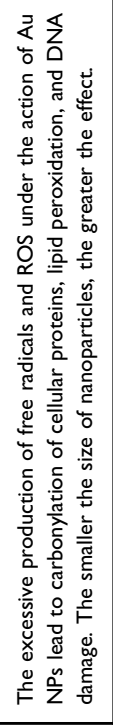 & 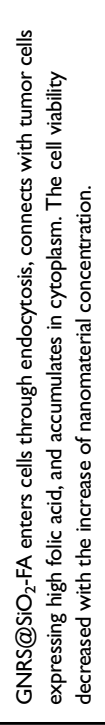 & 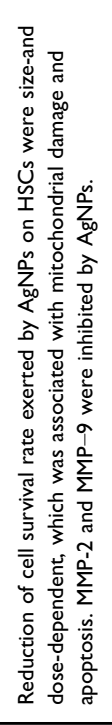 & \multicolumn{2}{|c|}{ 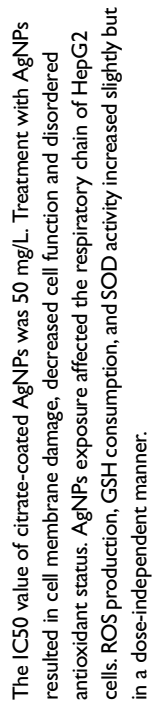 } & 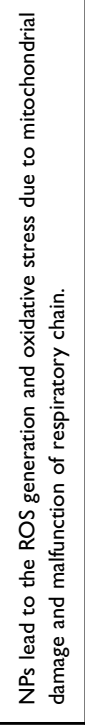 & 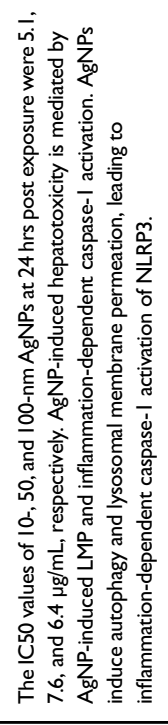 & 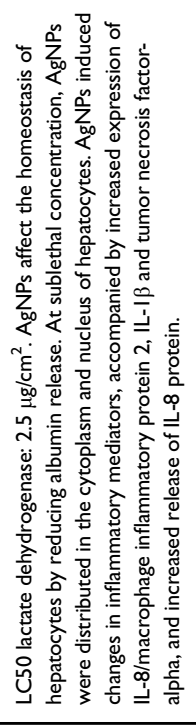 & 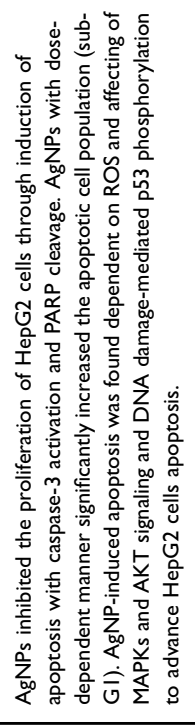 & 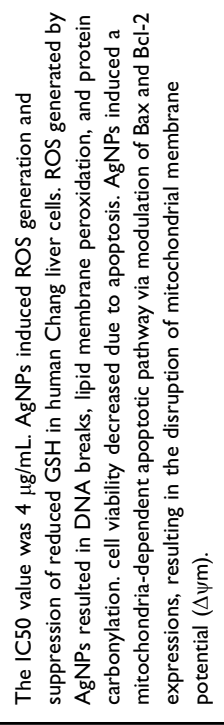 \\
\hline$\stackrel{0}{\xi}$ & $\begin{array}{l}\stackrel{\underline{n}}{\underline{L}} \\
\stackrel{m}{2} \\
\underline{0}\end{array}$ & 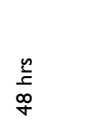 & $\begin{array}{l}\frac{n}{E} \\
\frac{\mathscr{L}}{\circ}\end{array}$ & \multicolumn{2}{|l|}{ 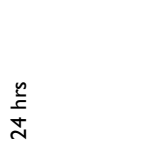 } & $\begin{array}{l}\frac{n}{c} \\
\stackrel{+}{N}\end{array}$ & 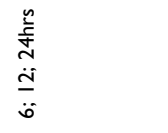 & $\begin{array}{l}\frac{n}{E} \\
\frac{d}{d}\end{array}$ & $\begin{array}{l}\stackrel{n}{E} \\
\end{array}$ & 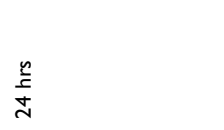 \\
\hline 足 & 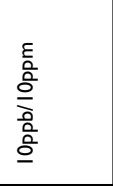 & 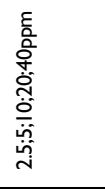 & 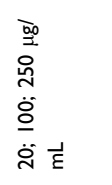 & \multicolumn{2}{|l|}{$\begin{array}{l}\overrightarrow{\underline{\varepsilon}} \\
\frac{\underline{0}}{\mathrm{~g}} \\
\frac{8}{2} \\
\frac{0}{1}\end{array}$} & 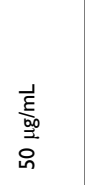 & $\begin{array}{l}\overrightarrow{\underline{\varepsilon}} \\
\frac{\mathrm{g}}{\mathrm{g}} \\
\frac{\mathrm{O}}{\mathrm{v}}\end{array}$ & 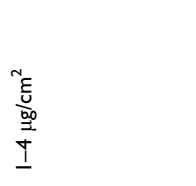 & 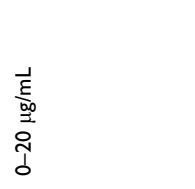 & $\begin{array}{l}\overrightarrow{\underline{\varepsilon}} \\
\frac{\mathrm{g}}{\mathrm{g}} \\
\frac{0}{0} \\
\frac{0}{0}\end{array}$ \\
\hline$\overline{\bar{u}}$ & $\begin{array}{l}\tilde{O} \\
\stackrel{0}{I} \\
\frac{0}{I}\end{array}$ & $\begin{array}{l}\text { ত̃ } \\
\stackrel{0}{I}\end{array}$ & $\begin{array}{l}\tilde{u} \\
\text { In }\end{array}$ & \multicolumn{2}{|l|}{ 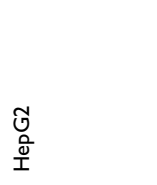 } & 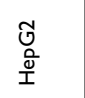 & 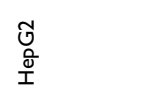 & ర્રુ & $\begin{array}{l}\tilde{O} \\
\stackrel{0}{I} \\
\frac{0}{I}\end{array}$ & 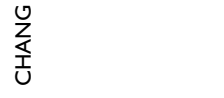 \\
\hline r & 1 & 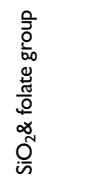 & $\frac{n}{a}$ & 苞 & $\stackrel{x}{a}$ & 1 & $\frac{n}{2}$ & 1 & 1 & 1 \\
\hline 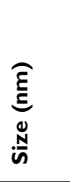 & $\begin{array}{l}\stackrel{0}{0} \\
\stackrel{\rho}{\rho} \\
\stackrel{0}{0}\end{array}$ & $\begin{array}{l}\text { 午 } \\
\text { q }\end{array}$ & $\begin{array}{l}0 \\
\hat{h} \\
0 \\
\underline{m} \\
\underline{0}\end{array}$ & 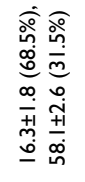 & 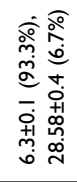 & 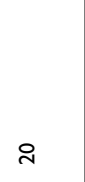 & $\begin{array}{l}\frac{8}{i n} \\
\hat{n} \\
\underline{0}\end{array}$ & i & N & 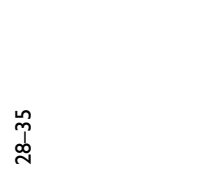 \\
\hline$\frac{n}{z}$ & 疋 & ₹ & 年 & 年 & 我 & $\mathbb{C}^{100}$ & $\stackrel{20}{\not<}$ & \&o & $\dddot{\infty}$ & $\dddot{80}$ \\
\hline ڤે & 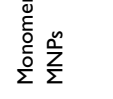 & & & & & & & & & \\
\hline
\end{tabular}




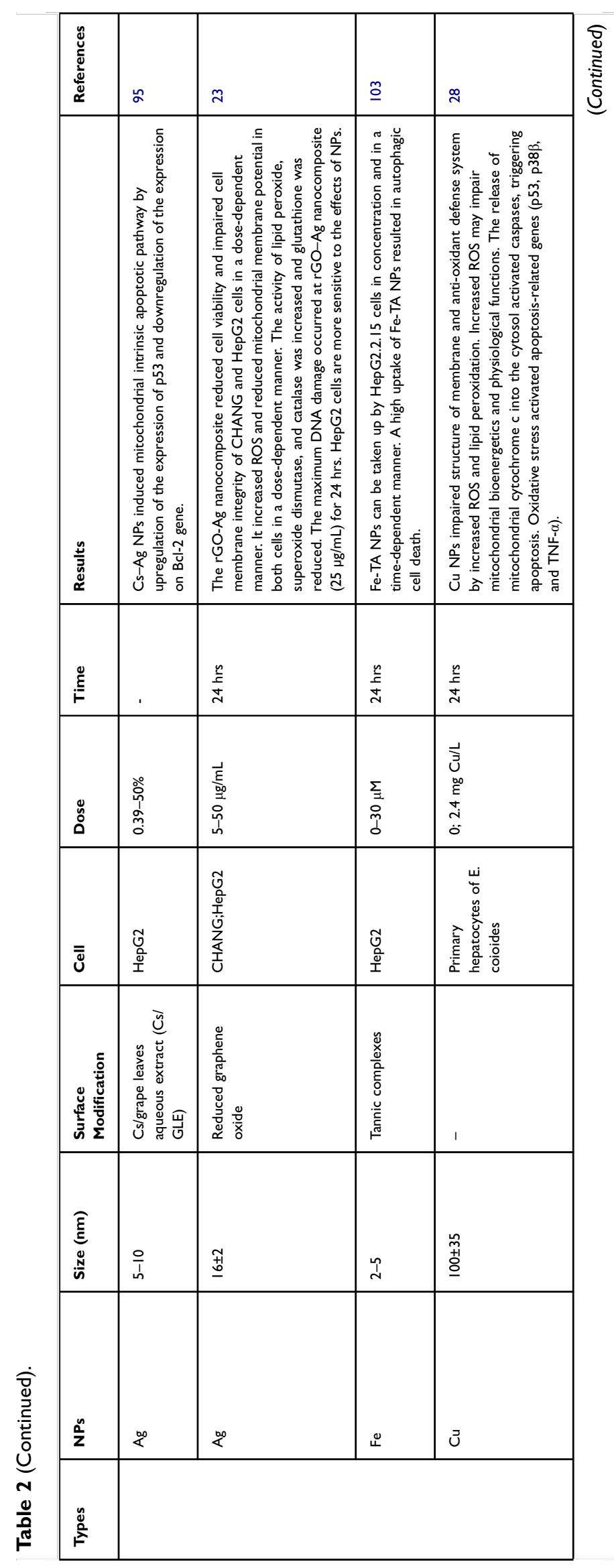




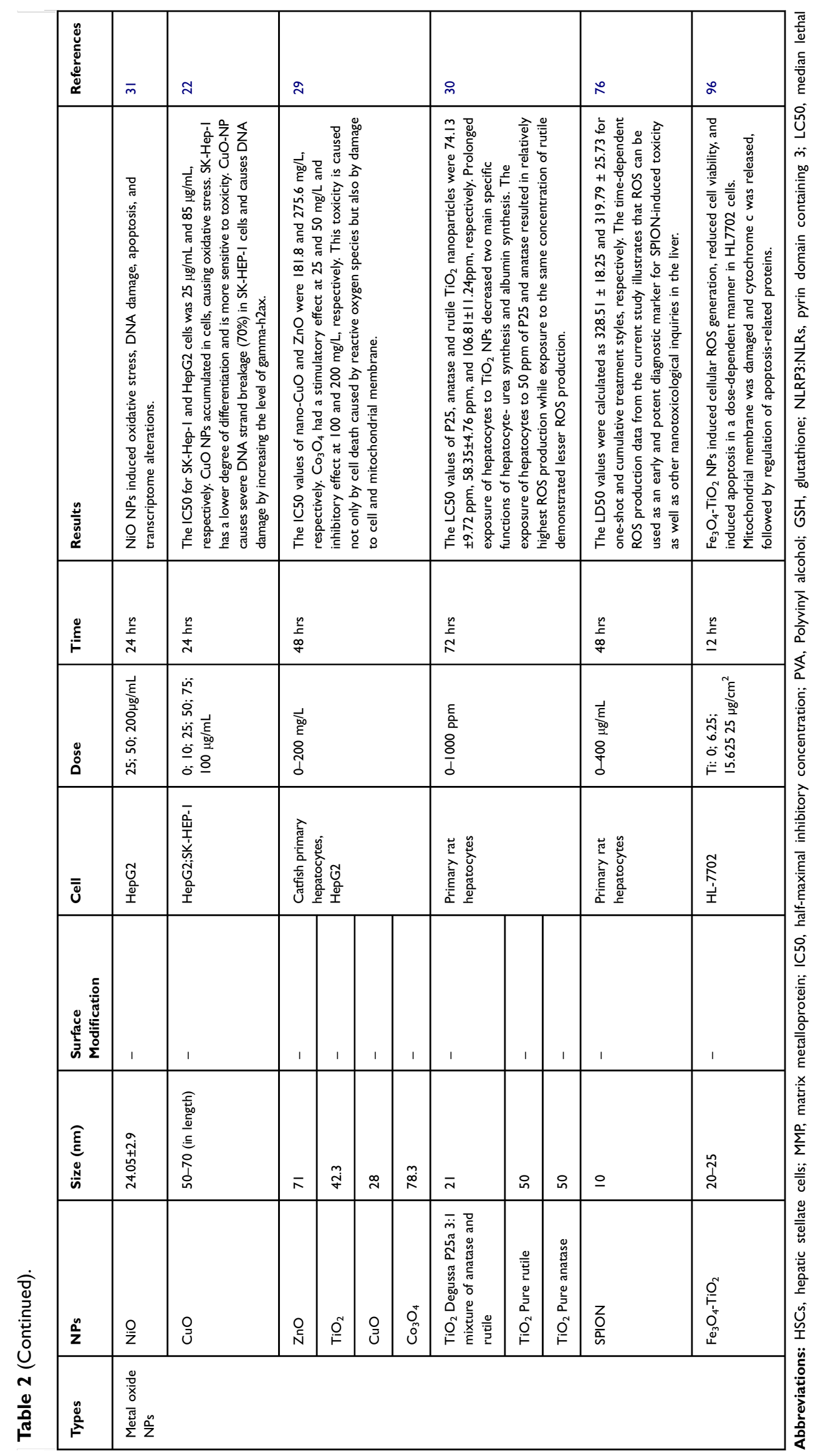

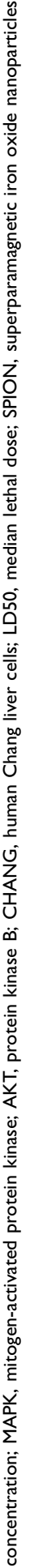


that MNPs can destroy the function of mitochondria and cell respiratory transmission. ${ }^{24,25}$ MNPs induced decrease of ATP levels, activated the signaling pathway of inflammation, apoptosis, and autophagy. ${ }^{26-28}$ The changes in oxidative stress and inflammatory factors suggest the mechanism of cell fate induced by MNPS..$^{24,29,30}$ In addition, MNPs can also damage DNA, which may explain the cause and mechanism of liver damage caused by MNPs at the organelle and molecular level. ${ }^{31}$

\section{Effects Of MNPs On Organelles}

A small organ-like structure present inside the cell is called a cell organelle, which is the basic structural, functional, and biological unit of all known living organisms. The integrity of organelle determines the fate of the cell. Liver cell membrane is sensitive to free radical and lipid peroxidation injury. Liver cell membrane injury was characterized by decreased fluidity and increased permeability. Wang et $\mathrm{al}^{29}$ found that $\mathrm{ZnO}$ NPs were distributed in the nucleus or concentrated on the surface of primary hepatocytes membrane microvilli and other organelles in catfish. Under light micrographs, numerous MNPs caused changes in cell membrane permeability, as well as distinct damages under TEM. According to Vrček et al, ${ }^{24}$ treatment of Ag NPs and Ag ion on human hepatocytes both led to cell membrane damage, which was manifested as LDH leakage and decreased albumin synthesis with ALT activity inhibited. Changes in liver membrane fluidity can damage the enzyme activity, receptor and transportation function, and inhibit the function of liver cells. The internal structure of the membrane may be disturbed by MNPs, as they can cause changes in membrane permeability by causing the plasma membrane to partially dissolve and form pore structures. The exposure of $\mathrm{MoS}_{2}$ NPs made reduction of the phospholipid bilayer domain of the liver cancer cells and an increase in membrane fluidity. ${ }^{33}$

The nucleus controls the cellular genetic material and plays an important role in cell growth, metabolism, proliferation, and differentiation. MNPs reached the nucleus and affected genetic materials, thus destroying nuclear morphology, damaging DNA, and affecting gene expression concretely. ${ }^{34}$ The mouse hepatocyte exposed to ZnO NPs exhibited karyopyknosis, nuclear membrane irregularity with indentation, and chromatin fragmentation. Shrunken micronuclei of hepatocytes with reticular-pattern chromatin condensation and apoptotic activity were further observed. ${ }^{35} \mathrm{TiO}_{2} \mathrm{NPs}$ orally administered into C57/BL6 mice caused liver metabolic genes (Oatp1, Mrp3, Cyp2b10, Cyp2c37) to increase under high dose treatment. ${ }^{36} \mathrm{TiO}_{2}$ NPs can also regulate the expression of mRNA p53 and the downstream genes regulating DNA damage response (p21 mdm2, gadd45) temporarily. Also, exposure of HepG2 cells to $\mathrm{TiO}_{2} \mathrm{NPs}$ resulted in DNA strand breakage and sustained growth of purine oxide. ${ }^{37}$ Overall, MNPs could cause intracellular DNA damage, which induced different cell outcomes, for example, activating caspase-3 and caspase-7 mediated apoptosis, ${ }^{25,38,39}$ regulating relevant genes (Bax, Puma, Noxa), ${ }^{39}$ and promoting caspase-1 induced pyroptosis. ${ }^{38}$

Mitochondrial dysfunction enticed by MNPs included morphological changes, increased production of ROS, changes in calcium content, descending mitochondrial membrane potential, inhibition of various enzyme activities, inhibition of electron transport chains, inhibition of cellular respiration, decline of ATP synthesis, etc., which could further lead to insufficient energy supply and affect cell viability such as apoptosis and necrosis. ${ }^{40,41} \mathrm{ZnO}$ NPs caused a series of morphological changes in mouse hepatocyte mitochondria, such as enlargement, elongation, angulations, swelling, cristolysis, lacked cristae, and ruptured membranes. ${ }^{35}$ Apart from morphological changes, three types of $\mathrm{TiO}_{2} \mathrm{NPs}$ (commercially available rutile, anatase, P25) induced oxidative stress in primary rat hepatocyte, downregulated mitochondrial dynamin OPA-1 and mitochondrial fusion protein MFN-1 gene expression, significant loss of mitochondrial membrane potential (MMP), and decreased activity of mitochondrial Mn-SOD enzyme. $^{30}$

Endoplasmic reticulum (ER) changes caused by MNPs include endoplasmic reticulum swelling, endoplasmic reticulum stress, misfolding of proteins, and increasing or decreasing protein synthesis. ${ }^{42,43}$ In liver, ER plays an important role in the synthesis of protein and steroid hormones, as well as promoting lipid metabolism and calcium storage. ER damage is related to the loss of protein synthesis initiation and liver detoxification function. The ER of mouse hepatocytes treated with ZnO NPs demonstrated ER pleomorphism in the form of dilatation, loss of parallel arrays, stacks shortening, vesiculation, upregulated transcription of genes encoding ER-resident molecular chaperones such as Grp78, Grp94, pdi-3 and $\mathrm{xbp}-1$, and accelerated the process of protein kinase R-like reticulum kinase (PERK) and eukaryotic initiation factor $2 \alpha$ (eIF $2 \alpha$ ) phosphorylation. ER stress is considered to be one of the early sensitive indicators of cytotoxicity caused by MNPs. ${ }^{35,44}$ Chen et al showed that the level of xbp-1s and Chop mRNA elevated with mice exposed to Ag NPs. 
In addition, the upregulation of ER stress marker proteins (hsp70, bip, p-ire1, p-perk, and chop) was dose-dependent for Ag NPs exposure. ${ }^{34}$ Ultra-small superparamagnetic iron oxide nanoparticles (USPIO-NP) act on L02 cells, causing the expansion and vacuolation of ER, and increasing the level of calcium ions in ER cavity. ER stress and unfolded protein response to PERK/ATF4 signaling pathway were finally activated. ${ }^{45}$

MNPs enter lysosomes mainly through passive diffusion or endocytosis, causing changes in lysosomal structure. ${ }^{46}$ The destruction of lysosomal cristae in Kupffer cells was obviously observed in rats injected intraperitoneally with an interval of $48 \mathrm{hrs}^{47} \mathrm{ZnO}$ NPs entered the lysosome mainly through endocytosis, leading to damage to lysosomal morphology during the interaction with the acidic environment, releasing a large amount of $\mathrm{Zn}^{2+}$ to the cytoplasm. And $\mathrm{Zn}^{2+}$ captured partially by mitochondria triggered the generation of ROS, causing mitochondrial dysfunction and apoptosis of cells. ${ }^{46}$ MNPs released ions under the lysosomal acidic environment, and then the lysosomal membranes were ruptured by MNPs or ions and the contents entering the cell lead to damage. ${ }^{38,48}$ Low-dose Ag-NPs $(10 \mu \mathrm{g} / \mathrm{mL})$ activated autophagic lysosome pathway in HepG2 cells and found increased level of lysosome activity, LC3-II protein expression, caspase-1, and IL-1 beta levels. Using ATG5 siRNA or chloroquine to destroy the autophagic pathway, Ag NPs induced increased caspase-1 activation and LDH release, suggesting that Ag NPs induced-cytotoxicity is associated with lysosomes damage and inflammatory bodies. ${ }^{26}$

\section{Properties Of Metal Nanomaterials Affect Cell Absorption And Distribution Of MNPs}

Toxicity of MNPs is largely dependent on cellular uptake and subcellular distribution. The size and surface properties of MNPs and the types of liver cells play a critical role in determining the outcome of interaction with the cells and other biological entities. ${ }^{49}$

\section{Size}

Size is a key factor determining the subcellular distribution. Numerous researches have indicated that MNPs, which mainly distributed in lysosome, cytoplasm, and nucleus, enter cells through endocytosis. ${ }^{50-52}$ When comparing three different sizes $(8.9 \mathrm{~nm}, 27.6 \mathrm{~nm}, 56 \mathrm{~nm})$ of gold NPs exposed HepG2 cells, the size of MNPs between 3 and 10 $\mathrm{nm}$ entered the nucleus, while the particles of 25 to $60 \mathrm{~nm}$ accumulated in the cytoplasm, which indicated the size is a key factor to determine the subcellular distribution. ${ }^{50}$ Another study showed that the shape of Au NPs affected the ratio of endocytosis. The highest cell uptake was triangular, followed by rod-shaped and star-shaped ${ }^{53}$ It is worth noting that the phenotype, internalization, and dissociation kinetics of each type of cells in liver have impacts on the quantity and absorption rate to hepatocytes, ${ }^{38,54,55}$ which will ultimately determine the liver toxicity caused by MNPs. Previous studies have shown that the liver preferentially cleans larger nanomaterials. ${ }^{56,57}$ Because of their higher surface ligand density, they were more likely to be absorbed by primary rat Kupffer cells as well as immortalized mouse macrophages. ${ }^{55}$

\section{Surface Modification}

The interaction between nanomaterials and cells begins with the recognition of surface ligands and biofilm receptors. Current research is devoted to the surface modification of innovative materials to improve the specificity of cell recognition. Sykes et $\mathrm{al}^{56}$ studied the binding of nanoparticles to MDA-MB-435 cancer cells. It was found that within 60 nanometers, transferrin-modified ANP could be absorbed by cancer cells more quickly, while PEG-coated materials could penetrate into cancer cells more deeply, but the absorption rate was slow. Surface modification reduces the toxicity of some metal nanomaterials. Gao et $\mathrm{al}^{8,51,58}$ synthesized a spherical silicon-coated gold nanomaterial (GNRS@SIO $\mathrm{SI}_{2}$ ), which was conjugated with amino terminus by folic acid as receptor, and finally produced GNRS@ $\mathrm{SiO}_{2}$-FA. In the concentration range of $0-40 \mathrm{ppm}$, the composite has almost no toxic effect. Compared with unmodified GNRS@ $\mathrm{SiO}_{2}$, the material can enter HepG2 cells quickly and distribute in cytoplasm and nucleus, while the internalization of unmodified nanomaterials is not obvious. Surface modification with enhanced biocompatibility can be used as an ideal material for targeted cancer therapy. ${ }^{59}$ Magnetic nanoparticle-aptamer probe demonstrates efficient in vitro MR imaging of the cancer cells and enhanced delivery of an anticancer drug into the cancer cell. ${ }^{60}$ Christopher et $\mathrm{al}^{61}$ modified NPs with bilayer nano-chitosan mercaptan and phosphatidylcholine and found that HepG2 cells consumed more new materials than gold polyvinyl glycol nanoparticles. Further studies showed that the structure of phosphatidylcholine-modified nanoparticles was similar to that of liposomes in hepatocytes, which enhanced the transport of gold nanoparticles. In vivo, the biodegradation and removal rate of PEG nanoparticles in liver and spleen is faster because PEG nanoparticles are more specific to tumors. ${ }^{62}$ Surface 
modification of metallic nanomaterials can enhance electrocatalytic activity. $\mathrm{TiO}_{2}{ }^{63}$ and $\mathrm{CeO}_{2}{ }^{64}$ nanocomposites modified by platinum nanoparticles enhanced the electrocatalytic activity of the materials for redox reaction. This may be due to the increase of oxygen capacity caused by strong electron coupling between composite structures.

\section{Ion Release And Solubility}

MNPs have the character of ion release. The toxicity of nano metallic monomer and metallic oxide not only comes from the NPs themselves but also from the release of metal ions or their interaction. Biological effects of MNPs in cells are shown to be mainly caused by the exposure to solubilized metallic ions. Han et $\mathrm{al}^{65}$ found that some MNPs decreased the activity of LDH. The similar deactivation mode of $\mathrm{Cu}^{2+}$ indicates that the decrease of $\mathrm{LDH}$ activity is mainly due to the dissolution of $\mathrm{Cu}$ NPs. Kinetic analysis showed that the $\mathrm{Cu}$ content in blood of $\mathrm{Cu}$ NPs exposed rats was $15-25 \%$ lower than that exposed by $\mathrm{Cu}^{2+}$. The $\mathrm{Cu}$ level in the organs (especially in the liver, kidney, and spleen) of the treated rats significantly increased. In the blood and organs of rats treated with $\mathrm{Cu}^{2+}$ and $\mathrm{Cu}$, respectively, $\mathrm{Cu}$ reached the highest level later and lasted for a shorter time. ${ }^{66} \mathrm{Zn}^{2+}$ and $\mathrm{ZnO}$ NPs can increase the $\mathrm{Zn}$ content of liver metallothioneins (MTs) and vitellogenin-like protein in plasma. It is noteworthy that MTs were upregulated by $\mathrm{Zn}^{2+}$ and $\mathrm{ZnO}$ NPs exposure, and the combination of $\mathrm{Zn}$ and $\mathrm{Cu}$ with MTs increased. ${ }^{67}$

The different results of subcellular distributions revealed that liver has different detoxification pathways for $\mathrm{ZnO} \mathrm{NPs}$ and $\mathrm{Zn}^{2+}$. Metallothionein-like protein was the main effector of $\mathrm{Zn}^{2+}$, and $\mathrm{ZnO}$ NPs were mainly related to metal-rich granule.${ }^{68}$ IvanaVinkovi Vrček et al ${ }^{24}$ compared the toxic effects of silver NPs and silver ions on HepG2 cells and found that the absorption of silver in the two forms was almost the same; the half-maximal inhibitory concentration (IC50) value of Ag NPs $(50 \mathrm{mg} / \mathrm{L})$ was about 100 times higher than the corresponding value of $\mathrm{Ag}^{+}\left(0.5 \mathrm{mg} \cdot \mathrm{L}^{-1}\right)$. The possible reason was that $\mathrm{Ag}^{+}$ directly combined with SOD and GSH-Px and inhibited the enzyme activity.

\section{Mechanisms of hepatotoxicity induced by metallic nanoparticles Oxidative Stress}

Reactive oxygen species (ROS) are active molecules produced during cell metabolism. In biology, ROS refers to superoxide anion radicals, hydroxyl radicals, and hydrogen peroxide. $^{69}$ ROS are produced in the process of mitochondrial and cytoplasmic oxidation and help maintain cell function in the process of cell physiology. Excessive production of ROS can break the redox balance, resulting in oxidative stress, which leads to cell damage and cell death. Previous studies have shown that oxidative stress leads to lipid peroxidation and hepatocyte apoptosis, which is related to the occurrence and development of hepatitis, liver failure, ischemia-reperfusion injury, alcoholic liver disease, and other diseases. ${ }^{70}$

MNPs accumulated in the liver cause oxidative stress by altering the content and activity of antioxidant enzymes. The process of oxidative stress is accompanied by increased activity of antioxidant enzymes such as SOD, CAT, and glutathione peroxidase (GSH-px), as well as activity of non-enzymatic antioxidants such as ascorbic acid (ASA) and GSH. ${ }^{71}$ Due to the combined action of Ag NPs and Ti NPs, oral exposure in rats caused a strong level of oxidative stress in the liver. The endogenous antioxidant system showed decreased GSH/GSSG ratio and increased formation of reactive substances. ${ }^{72}$ After administration of polyvinylpyrrolidone-coated AgNPs (PVP-AgNPs) in male Sprague Dawley rats, the activities of SOD, CAT and TBARS increased and showed a dosedependent effect. ${ }^{73}$ In addition, $\mathrm{Fe}_{3} \mathrm{O}_{4}$ NPs treatment caused significant increase in enzyme activities of GSHPx, GR, and glutathione s-transferase (GST) with decrease in GSH content in Wistar rat organs. ${ }^{74}$

Oxidative stress injury is closely related to mitochondrial changes. $\mathrm{TiO}_{2}$ NPs can produce excessive ROS and reduce the antioxidant capacity of cells by destroying mitochondria. Further observations showed that $\mathrm{TiO}_{2}$ NPs could significantly reduce the mRNA levels of various detoxifying enzymes in the liver of mice, including SOD, CAT, GSH-px, and MT. Cytochrome P450, family 1, subfamily A, polypeptide 1 (CYP1A1), and heat shock protein 70 (HSP70) also came down by NPs and were involved, respectively, in toxic metabolism and DNA repair of hepatocyte damage. ${ }^{75}$

In vitro studies, $\mathrm{Fe}_{3} \mathrm{O}_{4} \mathrm{NPs}$ exposure to primary rat hepatocytes showed that the excessive production of ROS was mainly due to the damage of mitochondria by MNPs. ${ }^{76}$ The possible reason for excessive ROS production through mitochondria by MNPs was the accumulation of calcium ions, which interferes with the electron transport chain of mitochondria and makes mitochondria produce more oxygen-free radicals. ${ }^{77}$ Another study also confirmed that the effect of $\mathrm{TiO}_{2}$ NPs on HepG2 cells could activate NF-E2-related factor 2 (Nrf2) signals. ${ }^{78}$ In 
addition, the damage of ROS induced by MNPs to the production of endoplasmic reticulum cannot be ignored. $\mathrm{ZnO}$ NPs consumed antioxidants in the liver and induced ROS to affect the structure and function of the endoplasmic reticulum of mouse hepatocytes, which is believed to be related to apoptosis and autophagy. ${ }^{44}$

The results of ROS and antioxidant enzymes induced by MNPs are closely related to cell differentiation. Mei-Lang et $\mathrm{al}^{22}$ compared the effects of $\mathrm{CuO}$ NPs on different cells of cancer cell lines, showing that excessive $\mathrm{CuO}$ NPs can induce alter membrane permeability, damage the mitochondrial respiratory chain, and break DNA strands. Cells eventually died. SK-Hep-1 cells could not effectively remove the accumulated hydrogen peroxide due to low differentiation level and inadequate activity of CAT and GRx. SKHep-1 cells are more sensitive to oxidative stress induced by $\mathrm{CuO}$ NPs than HepG2 cells, and the cell damage is more serious.

\section{Inflammation}

Inflammation promotes the necrosis of parenchymal cells in organs and increases the accumulation of extracellular matrix in tissues. Mild damage leads to fibrosis while severe damage can lead to changes in the structure of organs and tissues. MNPs entering the body or liver cells induce inflammation. Liu et al showed that the liver of male Wistar rats was infiltrated by inflammatory cells because of exposure to $\mathrm{ZnO} \mathrm{NPs}, \mathrm{TiO}_{2} \mathrm{NPs}$, and $\mathrm{Ag}$ NPs. Steatosis of hepatocytes and necrosis of the central part of hepatic lobules were also observed. Serum IL-1 $\beta$ level increased significantly in MNP-exposed group, serum IFN- $\gamma$ and TNF- $\alpha$ level decreased in $\mathrm{ZnONP}$ and $\mathrm{TiO}_{2}$ NP groups as well as the concentrations of TNF- $\alpha$ increased significantly in Ag NP groups. ${ }^{79}$ Kupffer cells, a kind of phenotype, are the resident macrophages in liver. MNPs accumulated in the liver are mainly ingested by Kupffer cells, with little uptake for hepatocytes, inflammation of the liver, Kupffer cells proliferation, and increased IL-1 $\beta$ release. ${ }^{38,55}$ Similar to the effect of Ag NPs on the expression of inflammation in vivo, the exposure of human hepatocyte line C3a to Ag NPs increased the expression of IL-8, macrophage inflammatory protein 2, IL-1RI, and tumor necrosis factor $\alpha(\mathrm{TNF}-\alpha){ }^{80} \mathrm{Ag} \mathrm{NPs}$ or $\mathrm{AgNO}_{3}$ contributed to the transition from hepatic steatosis to steatohepatitis. Ag NPs or AgNO3 acted on HFD mice caused the increase of serum total cholesterol, HDL, and LDL levels. More importantly, elevated levels of IL-6 and TNF in mouse liver suggested inflammation. ${ }^{13}$ The production of inflammation corpuscle NLRP3 is the core of inflammation induced by MNPs. The generation and activation of NLRP3 involve MAPK, NF-kB, and ROS signals. Manna et $\mathrm{al}^{81}$ showed that exposure to $\mathrm{Cu}$ NPs reduced liver index in a dose-dependent manner, resulting in oxidative stress and liver dysfunction. $\mathrm{Cu}$ NPs also increased the transcriptional activity of NF-kB. Ag NPs activated MAPK and PKB signaling pathways and induced ROSmediated DNA damage in HepG2 cells. ${ }^{82}$ These signals are not only related to inflammation but also induce ROS to promote apoptosis. $\mathrm{Cu}$ NPs affect CYP450 activity and

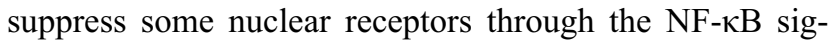
naling pathway. In fact, the regulation of $\mathrm{P} 450$ is also related to ROS. ${ }^{12}$

\section{The Outcomes Of Liver Cell Caused By MNPs}

MNPs which reach the liver enter the cells and cause damage to the liver cells. As the basic unit of liver, different forms of cell death cause a series of damage, leading to liver dysfunction and pathological changes. Recent studies have highlighted the role of different death pathways in the pathogenesis of liver injury induced by MNPs as described in Figure 1.

\section{Apoptosis}

Apoptosis is a programmed process of cell death that is used to clear unwanted cells from the body and a safe and controllable process that does not affect surrounding cells. ${ }^{83}$ Apoptosis of hepatocytes leads to dysfunction, proliferation inhibition, cycle arrest, and decreased viability, thus causing liver fibrosis, ${ }^{84}$ nonalcoholic fatty liver diseases related to cirrhosis and hepatocellular carcinoma (HCC). ${ }^{85}$ Apoptosis is also regarded as the basis for chronic inflammation. ${ }^{86}$

Apoptosis is a prominent feature of hepatic damage of MNPs. Hepatocyte apoptosis is characterized by nuclear chromatin condensation, nuclear rupture, cell contraction, plasma membrane vacuolation, DNA damage, lack of nutrition and cytokine release, which reflect the activation of cell surface death receptors and apoptotic factors.. ${ }^{87-90}$

Apoptosis is classified into endogenous apoptosis and exogenous apoptosis. Endogenous apoptosis, also known as mitochondrial pathway apoptosis, is a core event in which mitochondrial membrane permeability increases and mainly induced by activated $\mathrm{BH} 3$-only protein, which increases Bcl-2. Two proapoptotic molecules of the lymphoma 2 family, BAX (Bcl-2 related $\mathrm{X}$ protein) 


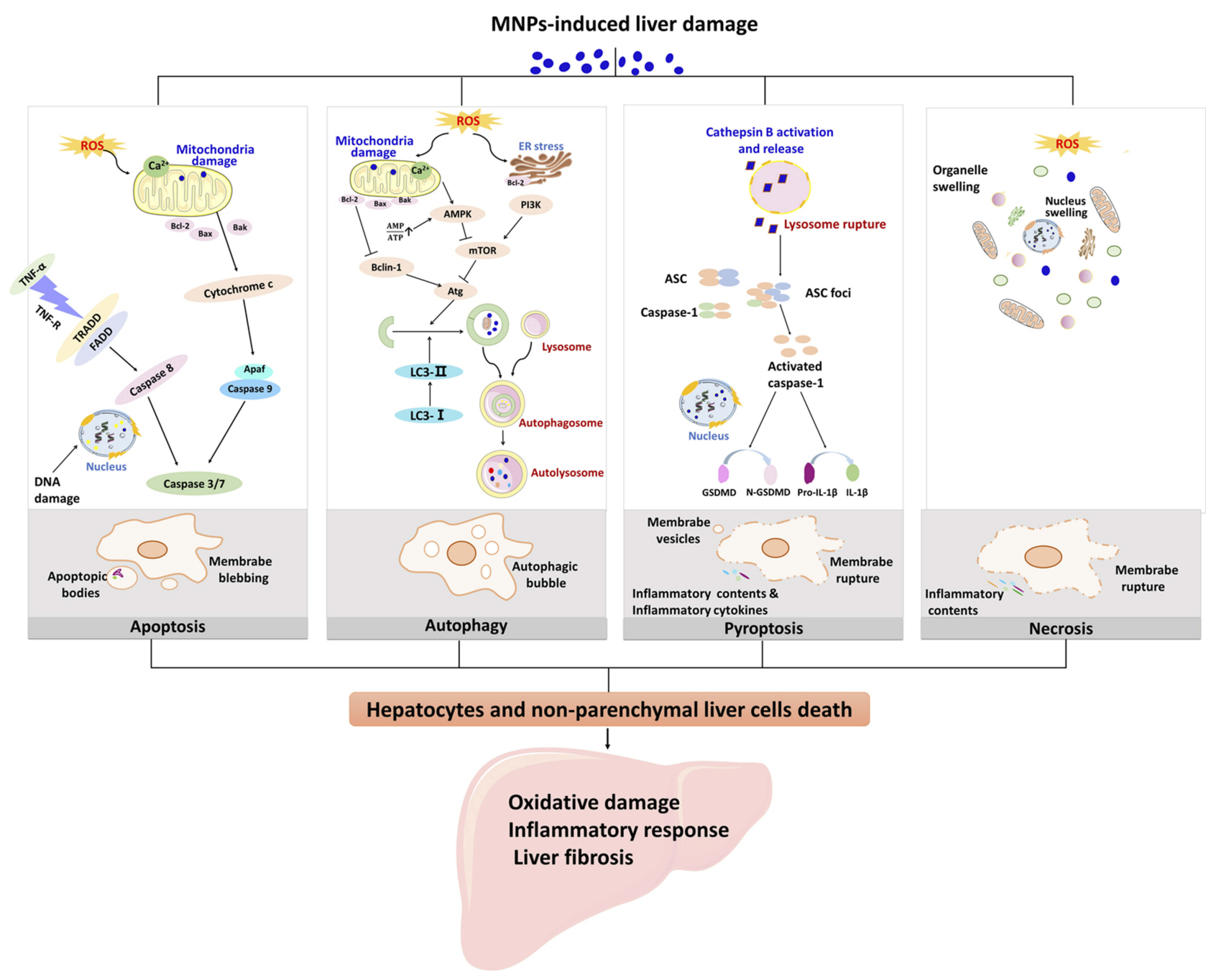

Figure I Different death mechanisms of liver cells are involved in the pathogenesis of liver injury induced by MNPs. Liver damage caused by MNPs is associated with oxidative damage, inflammatory response, and liver fibrosis in the liver. Apoptosis, autophagy, pyroptosis, and necrosis are all pathways of hepatocyte death. ROS induced by MNPs is responsible for the lipid peroxidation injury of the hepatic subcellular organelles. Apoptosis is considered as type I programmed cell death and mainly mediated by endogenous mitochondrial pathway and exogenous death receptor pathway. Mitochondrial ROS inhibited Bcl-2, and Fas-related death domain proteins (FADD) were activated, all of which eventually activated caspase 3 or caspase 7. Autophagy cell death is a programmed cell death different from apoptosis with initiation, nucleation of autophagosomes, phagosome expansion and completion, and autolysosome docking. Mitochondria and endoplasmic reticulum oxidative stress cause changes in the upstream molecules of autophagy and regulate autophagy-related (Atg) molecules. Pyroptosis is a form of inflammatory cell death that characterized by caspase-Idependent formation of plasma membrane pores, and mainly manifested by lysosome rupture, ROS production and the activation of inflammation, leading to the release of pro-inflammatory cytokines and cell lysis. Necrosis is due to the production of ROS or instability of lysosome, release of calpain, and decrease of ATP level. The characteristics of necrosis include plasma membrane rupture, mitochondrial swelling, lysosome rupture, and intracellular contents release. Cell necrosis leads to inflammation that is not related to caspase cascade.

and BAK (Bcl-2 antagonist or killer), form oligomers in the outer membrane of mitochondria, which constitute a supramolecular channel-mediated cytochrome $\mathrm{c} \square$ which causes other proteins to be released from the mitochondria into the cytoplasm, thereby activating Caspase 9 and the Caspase cascade, triggering endogenous apoptosis. ${ }^{91-93}$

For 40 adult male albino rats, histopathological examination of liver in the exposed group of $\mathrm{TiO}_{2} \mathrm{NPs}$ showed that oral administration of $\mathrm{TiO}_{2}$ NPs caused obvious apoptotic damage, which is manifested in the increase of Bax gene and the decrease of anti-apoptotic Bcl-2 gene level. ${ }^{94}$ Ag NPs entering human liver cells induced ROS production, inhibited the production of reduced glutathione, caused DNA fragmentation, lipid membrane peroxidation, and protein carbonylation. In addition, the mechanism of cell damage caused by Ag NPs is mitochondrial-dependent endogenous apoptotic pathway. By regulating the expression of Bax and Bcl-2, Ag NPs destroyed mitochondrial membrane potential, induced cytochrome c release in cytoplasm, and activated caspase- 9 and caspase- $3 .{ }^{27}$ Exposure 
of the liver cells (HL7702 cells, CHANG cells, HepG2 cells) to MNPs (Cs-Ag NPs, rGO-Ag NPs, $\mathrm{TiO}_{2}$ NPs, $\mathrm{Fe}_{3} \mathrm{O}_{4}-\mathrm{TiO}_{2} \mathrm{NPs}$ ) has been proved to have the same damage effects. ${ }^{23,95,96}$

Xue et $\mathrm{al}^{97}$ found that Ag NPs acting on HepG2 cells not only caused mitochondrial-dependent apoptosis induced by ROS but also activated the Fas death receptor pathway by downregulation of NF- $\kappa \mathrm{B}$ and activation of caspase- 8 and caspase-3. This process illustrates the death receptormediated exogenous apoptosis pathway.

Another crucial mechanism involved in apoptosis is mediated by JNK-activated ER stress. Yang et $\mathrm{al}^{44}$ showed that $\mathrm{ZnO}$ NPs significantly reduced the expression of antiapoptotic gene Bcl-2 in liver tissue of mice. The phosphorylation of JNK protein in mouse hepatocytes was activated, and the activities of caspase-3, caspase-9, and caspase-12 were observed.

\section{Autophagic Cell Death}

Autophagy, an important process of self-regulation and homeostasis of cells, is involved in cell cycle, cell death, self-renewal of stem cells, establishment of pluripotentinduced stem cells, and resistance to foreign pathogenic microorganisms. ${ }^{98}$ More and more studies have shown that autophagy, as a double-edged sword effect, plays a two-way regulating role in affecting cell survival and death. ${ }^{99}$ In liver metabolic diseases, autophagy is closely related to the occurrence of NAFLD, viral hepatitis, and even cancer. $^{100}$

Numerous studies have shown that MNPs activate autophagy after entering the liver cells by endocytosis. MNPs (CTAB-GNR NPs, Ag NPs) entered the L02 cells and HepG2 cells, activated low levels of autophagy, increased protein expression of LC3-II, and observed double-layer membrane-coated autophagosomes under TEM.At this concentration, no significant cytotoxicity and lysosomal damage were observed, and MNPs induced ROS-mediated protective autophagy. ${ }^{26,101}$ Rare earth doped up conversion nanoparticles (UCNs) activated autophagy in Kupffer cell $\square$ which causesd a decrease of cell survival and an increase in liver damage. However, inhibiting the formation of autophagosomes with 3-MA increased the survival rate of Kupffer cells and further eliminated the hepatotoxicity induced by UCNs, ${ }^{102}$ suggesting autophagy played a role in damaging cells.

Cells recognize MNPs as external stimuli, activate ROS, and then cause mitochondrial damage. In order to maintain cell stability, autophagy is used to remove dysfunctional organelles. Autophagic damage occurs when autophagy fails to cope with environmental changes. Fusion of autophages and lysosomes to form autophagic lysosomes is an important process of cell autophagy. Iron(III)-tannin complex (Fe-TA NPs) induced the endocytosis of HepG2 cells and initiated the formation of autophagosomes. The intracellular nuclear vesicles and multivesicular (MVBs) produced by Fe-TA NPs were fused with autophagosomes, which could be degraded by regulating lysosomal functions. $^{103}$ This could be considered as one of the mechanisms by which MNPs induce autophagic cell death from excessive self-digestion.

In addition, there is a close relationship between autophagy and apoptosis induced by MNPs in hepatocytes apoptosis may be an autophagy-related death pathway. In adult male SD rats exposed to PVP-Ag NPs, the ratio of LC3-II/LC3-I increased together with increased caspase-3, p53, and p21. ${ }^{73}$ Kermanizadeh et al ${ }^{104}$ cultured HepG2 cells and A549 cells with Ag and ZnO NPs for $6 \mathrm{hrs}$, resulting in the expression of autophagy-related genes LC3B, Atg4b, p62 upregulated, Atg12 and Atg5 declined. However, in the latter stages autophagy was impaired by caspase-dependent apoptotic cell death..

\section{Pyroptosis}

Pyroptosis, also referred to as cellular inflammatory necrosis, is one way of caspase-1-mediated programmed cell death. ${ }^{105}$ Gasdermin D (GSDMD) is one of the downstream Gasdermin protein families. The basic mechanism of the cell pyroptosis is that the inflammatory complex of the upstream protein activates caspase-1, which cleaves the GSDMD, and then the GSDMD protein releases the N-terminal fragment to recognize the phospholipid molecules on the cell membrane. Further, a hole is formed on the cell membrane, resulting in changes in ion concentration and osmotic pressure inside and outside the cell. Finally, the cell membrane is broken and cell contents are released, accompanied by pyroptosis. ${ }^{106-108}$

MNPs activated hepatocyte pyroptosis after entering cells by endocytosis. Its main features are cell membrane rupture and proinflammatory cell content release, which will cause the pathogen released from the dead cells, phagocytized and degraded by other cells, thus reducing the burden of infection, activating a strong inflammatory response and releasing plenty of inflammatory factors. ${ }^{109}$ In addition, MNPs could also cause liver nuclear condensation, DNA shearing, and fragmentation. ${ }^{110}$ Mirshafiee et $\mathrm{al}^{38}$ found that $\mathrm{Gd}_{2} \mathrm{O}_{3}$ could cause Kupffer cell swelling, 
giant blebbing, cell membrane pore, caspase-1 activation, and IL-1 $\beta$ creation. The formation of cell membrane pore depends on GSDMD, which activates caspase-1. It disturbs the ion flow inside and outside the cell membrane, causes cell swelling, forms membrane vesicles, and leads to the leakage and intracellular substances release. Therefore, the death pattern of macrophages and hepatic parenchymal cells caused by MNPs can be reversed by knocking out the Gastermin D protein.

The apoptosis induced by MNPs has been confirmed to be associated with autophagy. Ag NPs induce caspase-1 activation and autophagic flux in HepG2 cells. When the autophagy-lysosome system was blocked, NLRP3 inflammatory bodies activated caspase- 1 to a higher degree. ${ }^{26}$

The release of IL- $1 \beta$ and the increase of N-GSDMD expression induced by cell char death promote the occurrence and development of some liver diseases. ${ }^{111}$ N-GSDMA activates NLRP3 inflammatory bodies and induces cell death through typical pathways. ${ }^{112}$ The pathogenesis of hepatitis $\mathrm{C}$ has been confirmed to be closely related to caspase- 1 and caspase- 3 signal-mediated cell burnout. ${ }^{113}$

\section{Necrosis}

Cell necrosis refers to the irreversible loss of metabolic function and structural integrity of the cell serosa, the loss of integrity of the serosa, and the activation of non-inflammatory bodies. It is characterized by mitochondrial impairment and ATP depletion. ROS generation induced by MNPs leads to cell death and damage via hepatocyte necrosis. Adult female rats were continually exposed to $\mathrm{PbO}$ NPs $24 \mathrm{hrs}$ a day with an average concentration of $10^{6}$ particles per cubic centimeter. Six weeks later, the liver changed, showing hepatocyte swelling and hydropic degeneration, lobular hypertrophy with nuclear size changes, hepatocyte necrosis, inflammation around the portal vein and accumulation of lipid droplets. ${ }^{114}$ Wang et $\mathrm{al}^{28}$ co-cultured primary hepatocytes with $\mathrm{Cu}$ NPs and $\mathrm{CuSO}_{4}$ for $24 \mathrm{hrs}$ and observed that the apoptosis and necrosis rate of primary hepatocytes were apparently higher than that of control group. Significantly increased intracellular ROS and MDA, multiplied cytochrome c release, downregulated anti-oxidation related genes [SOD, CAT, GSH-Px4] expression, upregulated apoptosis-related genes (p53, p38 and TNF- $\alpha$ ), and increased activities of caspase- 3 , caspase- 8 , and caspase- 9 all indicated that ROS might be involved in the process of cell necrosis, and there could be a certain correlation between necrosis and apoptosis.
Necrosis is one of the prominent features in acute liver injury. ${ }^{115}$ Death of necrotic cells is also a distinct feature of hepatic ischemia/reperfusion injury. ${ }^{86}$ In chronic hepatitis B virus infection, from local inflammation led hepatocyte apoptosis and necrosis to liver regeneration, a vicious circle is formed, which may be the potential mechanism of hepatocellular carcinogenesis. ${ }^{116}$

\section{Outlook}

With the advances in the fields of nanotechnology, the potential exposure of MNPs is likely to increase, so there is an urgent need to further study the possibility of any detrimental health effects, target organ damage, and its mechanism. The toxicity of MNPs to the liver is an important basis for the safety assessment of MNPs. At present, studies on the hepatotoxicity of MNPs are still in their infancy. The toxicity of MNPs is mainly due to the special physical and chemical properties, such as size, surface chemical modification and metal ion release. The liver is particularly susceptible to MNPs because the liver has a much higher accumulation of NM than other organs.. For the evaluation of hepatotoxicity of MNPs, on the one hand, a full understanding of the distribution and metabolism of MNPs in the liver, and detecting the changes in liver function, degree of injury, and recovery of liver function in vivo $\square$ which are prerequisites for evaluating their liver toxicity. On the other hand, it is important to better understand the mechanisms by focusing on the complex biological process between MNPs and cells. MNPs entering cells change the structure and functions of organelles, affect the normal biological functions of cells, and ultimately impact the amount of toxicity and threshold dose caused by MNPs. It is worth noting that once the MNPs accumulate in the liver, it may cause changes in liver function. When the MNPs enter the cell, it will damage it and produce a large amount of free oxidative free radicals, thereby destroying the oxidation/deoxidation balance. MNPs can also enter the nucleus and can directly or indirectly destroy DNA, leading to changes in gene expression and even apoptosis. If there is a long-term liver injury, the HSC will turn into an active state. Along with changes in the activity of several intracellular signaling pathways, extracellular components are involved in the extracellular matrix, which ultimately leads to fibrosis and may eventually progress to cirrhosis. However, the detailed mechanism of MNPs leading to liver fibrosis remains unclear.

To study the molecular mechanisms of liver injury caused by MNPs, it is necessary to perform experiments from in vivo to in vitro involving in molecular biology especially biomarker 
screening, which is crucial for understanding the detailed mechanism of liver injury. Although immune inflammation, apoptosis, and oxidative stress related to liver injury have been investigated, the aspects of energy metabolism, protein metabolism, and lipid metabolism should be studied in detail. Current research into the toxicity of MNPs has been limited to animal experiments in vivo and in vitro; the relationship between subcellular damage and related mechanisms is still unknown. Therefore, the toxicology of MNPs must be studied in-depth to improve the quality and safety of those nanoparticles. Research in this area has a long way to go.

\section{Acknowledgements}

This work was supported by National Natural Science Foundation of China (No. 81673218, 21876026, 31671034), Student's Platform for Innovation and Entrepreneurship Training Program (No. 201810286142) and the Fundamental Research Funds for the Central Universities (No. 2242018K40021, 2242019K40223).

\section{Disclosure}

The authors report no conflicts of interest in this work.

\section{References}

1. Khan I, Saeed K, Khan I. Nanoparticles: properties, applications and toxicities. Arab J Chem. 2017;21(3):541-548.

2. Parada J, Rubilar O, Fernández-Baldo MA, et al. The nanotechnology among US: are metal and metal oxides nanoparticles a nano or mega risk for soil microbial communities? Crit Rev Biotechnol. 2018;39 (2):157-172. doi:10.1080/07388551.2018.1523865

3. Andra S, Balu SK, Jeevanandham J. Phytosynthesized metal oxide nanoparticles for pharmaceutical applications. Naunyn Schmiedebergs Arch Pharmacol. 2019;392(7):755-771. doi:10.1007/s00210-019-01666-7

4. Amde M, Liu JF, Tan ZQ, Bekana D. Transformation and bioavailability of metal oxide nanoparticles in aquatic and terrestrial environments. A review. Environ Pollut. 2017;230:250-267. doi:10.1016/j.envpol. 2017.06.064

5. Yah CS, Iyuke SE, Simate GS. A review of nanoparticles toxicity and their routes of exposures. Iran J Pharm Res. 2012;8(1):299-314.

6. Gustafson HH, Holt-Casper D, Grainger DW, Ghandehari H. Nanoparticle uptake: the phagocyte problem. Nano Today. 2015;10 (4):487-510. doi:10.1016/j.nantod.2015.06.006

7. Almeida JPM, Chen AL, Foster A, Drezek R. In vivo biodistribution of nanoparticles. Nanomedicine. 2011;6(5):815-835. doi:10.2217/nnm. 11.79

8. Li TZ, Gong F, Zhang BY, et al. [Acute toxicity and bio-distribution of silver nitrate and nano-silver with different particle diameters in rats]. Chin J Burns. 2016;32(10):606-612. doi:10.3760/cma.j.issn.10092587.2016.10.007

9. Kreyling WG, Möller W, Holzwarth U, et al. Age-dependent rat lung deposition patterns of inhaled 20 nanometer gold nanoparticles and their quantitative biokinetics in adult rats. ACS Nano. 2018;12 (8):7771-7790. doi:10.1021/acsnano.8b01826
10. Chinde S, Grover P. Toxicological assessment of nano and micron-sized tungsten oxide after 28days repeated oral administration to Wistar rats. Mutat Res. 2017;819:1-13. doi:10.1016/j.mrgentox.2017.05.003

11. Liu F, Chang X, Tian M, et al. Nano NiO induced liver toxicity via activating the NF- $\mathrm{kB}$ signaling pathway in rats. Toxicol Res (Camb). 2017;6(2):242-250. doi:10.1039/C6TX00444J

12. Tang H, Min X, Fei S, et al. Effects and mechanism of nano-copper exposure on hepatic cytochrome P450 enzymes in rats. Int $J$ Mol Sci. 2018;19(7):2140. doi:10.3390/ijms 19072140

13. Jia J, Li F, Zhou H, et al. Oral exposure of silver nanoparticles or silver ions may aggravate fatty liver disease in overweight mice. Environ Sci Technol. 2017;51(16):9334-9343. doi:10.1021/acs.est.7b02752

14. Azim SAA, Darwish HA, Rizk MZ, Ali SA, Mai OK. Amelioration of titanium dioxide nanoparticles-induced liver injury in mice: possible role of some antioxidants. Exp Toxicol Pathol. 2015;67 (4):305-314. doi:10.1016/j.etp.2015.02.001

15. Sha B, Gao W, Wang $\mathrm{S}$, et al. Oxidative stress increased hepatotoxicity induced by nano-titanium dioxide in BRL-3A cells and SpragueDawley rats. J Appl Toxicol. 2014;34(4):345-356. doi:10.1002/jat.2900

16. Magaye RR, Yue X, Zou B, et al. Acute toxicity of nickel nanoparticles in rats after intravenous injection. Int J Nanomedicine. 2014;2014(1):1393-1402.

17. Recordati C, De Maglie M, Bianchessi S, et al. Tissue distribution and acute toxicity of silver after single intravenous administration in mice: nano-specific and size-dependent effects. Part Fibre Toxicol. 2016;13:12. doi:10.1186/s12989-016-0124-x

18. Suker DK, Jasim FA. Liver histopathological alteration after repeated intra-tracheal instillation of titanium dioxide in male rats. Gastroenterol Hepatol Bed Bench. 2018;11(2):159-168.

19. Matthias B, Thomas R, Keul HA, et al. Peptide-functionalized gold nanorods increase liver injury in hepatitis. ACS Nano. 2012;6 (10):8767-8777. doi:10.1021/nn302502u

20. Wang C, Cheng K, Zhou L, et al. Evaluation of long-term toxicity of oral zinc oxide nanoparticles and zinc sulfate in mice. Biol Trace Elem Res. 2017;178(2):276-282. doi:10.1007/s12011-017-0934-1

21. Yu S, Liu F, Wang C, et al. Role of oxidative stress in liver toxicity induced by nickel oxide nanoparticles in rats. Mol Med Rep. 2018;17(2):3133-3139. doi:10.3892/mmr.2017.8226

22. Mei-Lang K, Shu-Ling H, Chih-Chung W, et al. Enhanced reactive oxygen species overexpression by $\mathrm{CuO}$ nanoparticles in poorly differentiated hepatocellular carcinoma cells. Nanoscale. 2015;7 (5):1820-1829. doi: $10.1039 / \mathrm{C} 4 \mathrm{NR} 05843 \mathrm{G}$

23. Ali D, Alarifi S, Alkahtani S, Almeer RS. Silver-doped graphene oxide nanocomposite triggers cytotoxicity and apoptosis in human hepatic normal and carcinoma cells. Int J Nanomedicine. 2018;13:5685-5699. doi:10.2147/IJN

24. Vrček IV, Žuntar I, Petlevski R, et al. Comparison of in vitro toxicity of silver ions and silver nanoparticles on human hepatoma cells. Environ Toxicol. 2016;31(6):679-692. doi:10.1002/tox.v31.6

25. Grzelak A, Wojewodzka M, Meczynska-Wielgosz S, Zuberek M, Wojciechowska D, Kruszewski M. Crucial role of chelatable iron in silver nanoparticles induced DNA damage and cytotoxicity. Redox Biol. 2018;15:435-440. doi:10.1016/j.redox.2018.01.006

26. Mishra AR, Zheng J, Tang X, Goering PL. Silver nanoparticle-induced autophagic-lysosomal disruption and NLRP3-inflammasome activation in HepG2 cells is size-dependent. Toxicol Sci. 2016;150(2):473-487. doi:10.1093/toxsci/kfw011

27. Piao MJ, Kang KA, Lee IK, et al. Silver nanoparticles induce oxidative cell damage in human liver cells through inhibition of reduced glutathione and induction of mitochondria-involved apoptosis. Toxicol Lett. 2011;201(1):92-100. doi:10.1016/j.toxlet.2010.12.010

28. Wang T, Chen X, Long X, Liu Z, Copper Nanoparticles YS Copper sulphate induced cytotoxicity in hepatocyte primary cultures of epinephelus coioides. PLoS One. 2016;11(2):e0149484. doi:10.1371/journal.pone. 0149484 
29. Wang Y, Aker WG, Hwang HM, Yedjou CG, Yu H, Tchounwou PB. A study of the mechanism of in vitro cytotoxicity of metal oxide nanoparticles using catfish primary hepatocytes and human HepG2 cells. Sci Total Environ. 2011;409(22):4753-4762. doi:10.1016/j.scitotenv.2011.07.039

30. Natarajan V, Wilson CL, Hayward SL, Kidambi S. Titanium dioxide nanoparticles trigger loss of function and perturbation of mitochondrial dynamics in primary hepatocytes. PLoS One. 2015;10(8): e0134541. doi:10.1371/journal.pone.0134541

31. Saquib Q, Siddiqui MA, Ahmad J, et al. Nickel oxide nanoparticles induced transcriptomic alterations in HEPG2 cells. Exp Biol Med. 2018;1048(10):163-174.

32. Sun X, Wang Z, Zhai S, Cheng Y, Liu J, Liu B. In vitro cytotoxicity of silver nanoparticles in primary rat hepatic stellate cells. Mol Med Rep. 2013;8(5):1365-1372. doi:10.3892/mmr.2013.1683

33. Liu S, Shen Z, Wu B, et al. Cytotoxicity and efflux pump inhibition induced by molybdenum disulfide and boron nitride nanomaterials with sheetlike structure. Environ Sci Technol. 2017;51(18):1083410842. doi:10.1021/acs.est.7b02463

34. Chen R, Zhao L, Bai R, et al. Silver nanoparticles induced oxidative and endoplasmic reticulum stresses in mouse tissues: implications for the development of acute toxicity after intravenous administration. Toxicol Res (Camb). 2016;5(2):602-608. doi:10.1039/C5TX00464K

35. Almansour M, Sajti L, Melhim W, Jarrar B. Ultrastructural hepatic alterations induced by $35 \mathrm{~nm}$ zinc oxide nanoparticles. Nanosci. 2015;7(9):763-769. doi:10.1166/nnl.2015.2028

36. Yang J, Luo M, Tan Z, et al. Oral administration of nano-titanium dioxide particle disrupts hepatic metabolic functions in a mouse model. Environ Toxicol Pharmacol. 2017;49:112-118. doi:10.1016/ j.etap.2016.12.006

37. Jana P, Bojana Z, Magdalena S, et al. DNA damage and alterations in expression of DNA damage responsive genes induced by $\mathrm{TiO} 2$ nanoparticles in human hepatoma HepG2 cells. Nanotoxicology. 2011;5(3):341-353. doi:10.3109/17435390.2010.507316

38. Mirshafiee V, Sun B, Chang $\mathrm{CH}$, et al. Toxicological profiling of metal oxide nanoparticles in liver context reveals pyroptosis in kupffer cells and macrophages versus apoptosis in hepatocytes. ACS Nano. 2018;12(4):3836-3852. doi:10.1021/acsnano.8b01086

39. Paesano L, Perotti A, Buschini A, et al. Markers for toxicity to HepG2 exposed to cadmium sulphide quantum dots; damage to mitochondria. Toxicology. 2016;374(2016):18-28. doi:10.1016/j. tox.2016.11.012

40. Nguyen KC, Rippstein P, Tayabali AF, Willmore WG. Mitochondrial toxicity of cadmium telluride quantum dot nanoparticles in mammalian hepatocytes. Toxicol Sci. 2015;146(1):31-42. doi: $10.1093 /$ toxsci/kfv068

41. Maurer LL, Meyer JN. A systematic review of evidence for silver nanoparticle-induced mitochondrial toxicity. Environ Sci Nano. 2016;3(2):311-322.

42. Kuang H, Yang P, Yang L, Aguilar ZP, Xu H. Size dependent effect of $\mathrm{ZnO}$ nanoparticles on endoplasmic reticulum stress signaling pathway in murine liver. J Hazard Mater. 2016;317:119-126. doi:10.1016/j.jhazmat.2016.05.063

43. Yu KN, Sung JH, Lee $\mathrm{S}$, et al. Inhalation of titanium dioxide induces endoplasmic reticulum stress-mediated autophagy and inflammation in mice. Food Chem Toxicol. 2015;85:106-113. doi:10.1016/j.fct.2015.08.001

44. Yang X, Shao H, Liu W, et al. Endoplasmic reticulum stress and oxidative stress are involved in $\mathrm{ZnO}$ nanoparticle-induced hepatotoxicity. Toxicol Lett. 2015;234(1):40-49. doi:10.1016/j. toxlet.2015.02.004

45. He C, Jiang S, Yao H, et al. Endoplasmic reticulum stress mediates inflammatory response triggered by ultra-small superparamagnetic iron oxide nanoparticles in hepatocytes. Nanotoxicology. 2018;12 (10):1198-1214. doi:10.1080/17435390.2018.1530388
46. Condello M, De Berardis B, Ammendolia MG, et al. $\mathrm{ZnO}$ nanoparticle tracking from uptake to genotoxic damage in human colon carcinoma cells. Toxicol In Vitro. 2016;35:169-179. doi:10.1016/j. tiv.2016.06.005

47. Sarhan OM, Hussein RM. Effects of intraperitoneally injected silver nanoparticles on histological structures and blood parameters in the albino rat. Int J Nanomedicine. 2014;9:1505-1517. doi:10.2147/IJN. S56729

48. Wang J, Yu Y, Lu K, et al. Silica nanoparticles induce autophagy dysfunction via lysosomal impairment and inhibition of autophagosome degradation in hepatocytes. Int J Nanomedicine. 2017;12:809825. doi:10.2147/IJN.S123596

49. Gatoo MA, Naseem S, Arfat MY, Mahmood Dar A, Qasim K, Zubair S. Physicochemical properties of nanomaterials: implication in associated toxic manifestations. Biomed Res Int. 2014;2014:498420. doi:10.1155/2014/498420

50. Lopez-Chaves C, Soto-Alvaredo J, Montes-Bayon M, Bettmer J, Llopis J, Sanchez-Gonzalez C. Gold nanoparticles: distribution, bioaccumulation and toxicity. In vitro and in vivo studies. Nanomed. 2018;14(1):1-12. doi:10.1016/j.nano.2017.08.011

51. Gao B, Xu J, He KW, et al. Cellular uptake and intra-organ biodistribution of functionalized silica-coated gold nanorods. Mol Imaging Biol. 2016;18(5):667-676. doi:10.1007/s11307-016-0938-9

52. Peng F, Su Y, Zhong Y, He Y. Subcellular distribution and cellular self-repair ability of fluorescent quantum dots emitting in the visible to near-infrared region. Nanotechnology. 2017;28(4):045101. doi:10.1088/1361-6528/28/4/045101

53. Xie X, Liao J, Shao X, Li Q, Lin Y. The effect of shape on cellular uptake of gold nanoparticles in the forms of stars, rods, and triangles. Sci Rep. 2017;7(1):3827. doi:10.1038/s41598-017-04229-Z

54. Almansour MI, Alferah MA, Shraideh ZA, Jarrar BM. Zinc oxide nanoparticles hepatotoxicity: histological and histochemical study. Environ Toxicol Pharmacol. 2017;51:124-130. doi:10.1016/j. etap.2017.02.015

55. Tsoi KM, MacParland SA, Ma XZ, et al. Mechanism of hardnanomaterial clearance by the liver. Nat Mater. 2016;15 (11):1212-1221. doi:10.1038/nmat4718

56. Sykes EA, Chen J, Zheng G, Chan WC. Investigating the impact of nanoparticle size on active and passive tumor targeting efficiency. ACS Nano. 2014;8(6):5696-5706. doi:10.1021/nn500299p

57. Perrault SD, Walkey C, Jennings $\mathrm{T}$, Fischer HC, Chan WC. Mediating tumor targeting efficiency of nanoparticles through design. Nano Lett. 2009;9(5):1909-1915. doi:10.1021/n1900031y

58. Suganthy N, Sri Ramkumar V, Pugazhendhi A, Benelli G, Archunan G. Biogenic synthesis of gold nanoparticles from terminalia arjuna bark extract: assessment of safety aspects and neuroprotective potential via antioxidant, anticholinesterase, and antiamyloidogenic effects. Environ Sci Pollut Res. 2018;25 (11):10418-10433. doi:10.1007/s11356-017-9789-4

59. Pugazhendhi A, Tnji E, Karuppusamy I, Kathirvel B. Inorganic nanoparticles: a potential cancer therapy for human welfare. Int J Pharm. 2018;539(1-2):104-111. doi:10.1016/j.jpharm.2018.01.034

60. Pilapong C, Sitthichai S, Thongtem S, Thongtem T. Smart magnetic nanoparticle-aptamer probe for targeted imaging and treatment of hepatocellular carcinoma. Int J Pharm. 2014;473(12):469-474. doi:10.1016/j.ijpharm.2014.07.036

61. England CG, Priest T, Zhang G, et al. Enhanced penetration into $3 \mathrm{D}$ cell culture using two and three layered gold nanoparticles. Int $J$ Nanomedicine. 2013;8:3603-3617. doi:10.2147/IJN.S51668

62. Jiang Z, Shan K, Song J, et al. Toxic effects of magnetic nanoparticles on normal cells and organs. Life Sci. 2019;220:156-161. doi:10.1016/j.lfs.2019.01.056

63. Krishnan SK, Kumar PSM. Controlled synthesis of Pt nanoparticle supported $\mathrm{TiO} 2$ nanorods as efficient and stable electrocatalyst for oxygen reduction reaction. J Mater Chem. 2018;6:46. 
64. Murphin Kumar PS, Thiripuranthagan S, Imai T, et al. Pt nanoparticles supported on mesoporous $\mathrm{CeO} 2$ nanostructures obtained through green approach for efficient catalytic performance towards ethanol electrooxidation. ACS Sustain Chem Eng. 2017;5:12. doi:10.1021/acssuschemeng.7b02019

65. Han X, Gelein R, Corson N, et al. Validation of an LDH assay for assessing nanoparticle toxicity. Toxicology. 2011;287(1):99-104. doi:10.1016/j.tox.2011.06.011

66. Lee IC, Ko JW, Park SH, et al. Comparative toxicity and biodistribution of copper nanoparticles and cupric ions in rats. Int $J$ Nanomedicine. 2016;11:2883-2900. doi:10.2147/IJN.S106346

67. Falfushynska H, Gnatyshyna L, Horyn O, Shulgai A, Stoliar O. A calcium channel blocker nifedipine distorts the effects of nano-zinc oxide on metal metabolism in the marsh frog Pelophylax ridibundus. Saudi J Biol Sci. 2019;26(3):481-489. doi:10.1016/j.sjbs.2017. 10.004

68. Wenhong F, Qian L, Xiuping Y, Li Z. Zn subcellular distribution in liver of goldfish (carassius auratus) with exposure to zinc oxide nanoparticles and mechanism of hepatic detoxification. PLoS One. 2013;8(11):e78123. doi:10.1371/journal.pone.0078123

69. Rang FJ, Boonstra J. Causes and consequences of age-related changes in DNA methylation: a role for ROS? Biology. 2014;3 (2):403-425. doi:10.3390/biology3020403

70. Cichożlach H, Michalak A. Oxidative stress as a crucial factor in liver diseases. World J Gastroenterol. 2014;20(25):8082-8091. doi:10.3748/wjg.v20.i25.8082

71. Liu H, Ma L, Liu J, Zhao J, Yan J, Hong F. Toxicity of nanoanatase TiOto mice: liver injury, oxidative stress. Environ Toxicol Chem. 2010;92(1):175-186.

72. Pereira LC, Pazin M, Franco-Bernardes MF, et al. A perspective of mitochondrial dysfunction in rats treated with silver and titanium nanoparticles (AgNPs and TiNPs). J Trace Elem Med Biol. 2018;47:63-69. doi:10.1016/j.jtemb.2018.01.007

73. Blanco J, Tomas-Hernandez S, Garcia T, et al. Oral exposure to silver nanoparticles increases oxidative stress markers in the liver of male rats and deregulates the insulin signalling pathway and p53 and cleaved caspase 3 protein expression. Food Chem Toxicol. 2018;115:398-404. doi:10.1016/j.fct.2018.03.039

74. Reddy UA, Prabhakar PV, Mahboob M. Comparative study of nano and bulk Fe3O4 induced oxidative stress in Wistar rats. Biomarkers. 2018;23(5):425-434. doi:10.1080/1354750X.2018.1443508

75. Jia X, Wang S, Zhou L, Sun L. The potential liver, brain, and embryo toxicity of titanium dioxide nanoparticles on mice. Nanoscale Res Lett. 2017;12(1):478. doi:10.1186/s11671-017-2242-2

76. Gokduman K, Bestepe F, Li L, Yarmush ML, Usta OB. Dose-, treatment- and time-dependent toxicity of superparamagnetic iron oxide nanoparticles on primary rat hepatocytes. Nanomedicine. 2018;13(11):1267-1284. doi:10.2217/nnm-2017-0387

77. Degli Esposti D, Hamelin J, Bosselut N, et al. Mitochondrial roles and cytoprotection in chronic liver injury. Biochem Res Int. $2012 ; 387626$.

78. Thai SF, Wallace KA, Jones CP, et al. Differential genomic effects of six different TiO2 nanomaterials on human liver HepG2 cells. $J$ Biochem Mol Toxicol. 2016;30(7):331-341. doi:10.1002/jbt.21798

79. Liu H-L, Yang H-L, Lin B-C, et al. Toxic effect comparison of three typical sterilization nanoparticles on oxidative stress and immune inflammation response in rats. Toxicol Res (Camb). 2015;4(2):486-493. doi:10.1039/C4TX00154K

80. Gaiser BK, Hirn S, Kermanizadeh A, et al. Effects of silver nanoparticles on the liver and hepatocytes in vitro. Toxicol Sci. 2013;131 (2):537-547. doi:10.1093/toxsci/kfs306

81. Prasenjit M, Manoranjan G, Jyotirmoy G, Joydeep D, Sil PC. Contribution of nano-copper particles to in vivo liver dysfunction and cellular damage: role of $\mathrm{I} \kappa \mathrm{B} \alpha / \mathrm{NF}-\kappa \mathrm{B}, \mathrm{MAPKs}$ and mitochondrial signal. Nanotoxicology. 2012;6(1):1-21. doi:10.3109/17435390. 2011.552124
82. Zhu B, Li Y, Lin Z, et al. Silver nanoparticles induce HePG-2 cells apoptosis through ROS-mediated signaling pathways. Nanoscale Res Lett. 2016;11(1):198. doi:10.1186/s11671-016-1419-4

83. Kerr JFR, Wyllie AH, Currie AR. Apoptosis_A basic biological phenomenon with wide-ranging implications in tissue kinetics. $\mathrm{Br} J$ Cancer. 1972;26(4):239-257. doi:10.1038/bjc.1972.33

84. Zhou WC, Zhang QB, Liang Q. Pathogenesis of liver cirrhosis. Med Klin. 2014;20(23):278-280.

85. Kanda T, Matsuoka S, Yamazaki M, et al. Apoptosis and nonalcoholic fatty liver diseases. World J Gastroenterol. 2018;24 (25):2661-2672. doi:10.3748/wjg.v24.i25.2661

86. Guicciardi ME, Malhi H, Mott JL, Gores GJ. Apoptosis and necrosis in the liver. Compr Physiol. 2013;3(2):977-1010. doi:10.1002/ cphy.c120020

87. Chen YY, Ou YS, Tao Y, et al. Effect and mechanisms of celastrol on the apoptosis of HOS osteosarcoma cells. Oncol Rep. 2018;40 (4):2260-2268. doi:10.3892/or.2018.6619

88. Savitskaya MA, Onishchenko GE. Mechanisms of apoptosis. Biochem.-Moscow. 2015;80(11):1393-1405. doi:10.1134/S000629 7915110012

89. Taylor RC, Cullen SP, Martin SJ. Apoptosis: controlled demolition at the cellular level. Nat Rev Mol Cell Biol. 2008;9(3):231-241. doi:10.1038/nrm2312

90. Günther C, Neumann H, Neurath MF, Becker C. Apoptosis, necrosis and necroptosis: cell death regulation in the intestinal epithelium. Gut. 2013;62(7):1062-1071. doi:10.1136/gutjnl-2011-301364

91. Adrain C, SJ M. The mitochondrial apoptosome_a killer unleashed by the cytochrome seas. Trends Biochem Sci. 2001;26(6):390-397. doi:10.1016/S0968-0004(01)01844-8

92. Arnoult D, Gaume B, Karbowski M, Sharpe JC, Cecconi F, Youle RJ. Mitochondrial release of AIF and EndoG requires caspase activation downstream of Bax_Bak-mediated permeabilization. Embo J. 2003;22(17):4385-4399. doi:10.1093/emboj/cdg423

93. Kitagawa N, Morikawa $\mathrm{T}$, Motai $\mathrm{C}$, et al. The antiproliferative effect of chakasaponins I and II, floratheasaponin A, and epigallocatechin 3-O-gallate isolated from camellia sinensis on human digestive tract carcinoma cell lines. Int J Mol Sci. 2016;17(12):116. doi:10.3390/ijms 17121979

94. Morgan A, Ibrahim MA, Galal MK, Ogaly HA, Abd-Elsalam RM. Innovative perception on using Tiron to modulate the hepatotoxicity induced by titanium dioxide nanoparticles in male rats. Biomed Pharmacother. 2018;103:553-561. doi:10.1016/j.biopha.2018.04.064

95. El-Sherbiny IM, Salih E, Yassin AM, Hafez EE. Newly developed chitosan-silver hybrid nanoparticles: biosafety and apoptosis induction in HepG2 cells. J Nanopart Res. 2016;18(7):172. doi:10.1007/ s11051-016-3477-z

96. $\mathrm{Su} \mathrm{H}, \mathrm{Li} \mathrm{Z}$, Lazar L, et al. In vitro evaluation of the toxicity and underlying molecular mechanisms of Janus $\mathrm{Fe}_{3} \mathrm{O}_{4}-\mathrm{TiO}_{2}$ nanoparticles in human liver cells. Environ Toxicol. 2018;33(10):10781088. doi:10.1002/tox.22631

97. Xue Y, Wang J, Huang Y, et al. Comparative cytotoxicity and apoptotic pathways induced by nanosilver in human liver HepG2 and L02 cells. Hum Exp Toxicol. 2018;37(12):1293-1309. doi:10.1177/0960327118769718

98. Glick D, Barth S, Macleod KF. Autophagy: cellular and molecular mechanisms. J Pathol. 2010;221(1):3-12. doi:10.1002/path.2697

99. Karen P, Manshian BB, Freya J, et al. Exploiting intrinsic nanoparticle toxicity: the pros and cons of nanoparticle-induced autophagy in biomedical research. Chem Rev. 2014;114(15):7581. doi:10.1021/cr400372p

100. Ueno T, Komatsu M. Autophagy in the liver: functions in health and disease. Nat Rev Gastroenterol Hepatol. 2017;14(3):170-184. doi:10.1038/nrgastro.2016.185

101. Wan J, Wang JH, Liu T, Xie Z, Yu XF, Li W. Surface chemistry but not aspect ratio mediates the biological toxicity of gold nanorods in vitro and in vivo. Sci Rep. 2015;5:11398. doi:10.1038/srep11398 
102. Zhu S, Zhang J, Zhang L, et al. Inhibition of kupffer cell autophagy abrogates nanoparticle-induced liver injury. Adv Healthc Mater. 2017;6(9):1-11. doi:10.1002/adhm.201601252

103. Saowalak K, Titipun T, Somchai T, Chalermchai P. Iron(III)-tannic molecular nanoparticles enhance autophagy effect and T1MRI contrast in liver cell lines. Sci Rep. 2018;8(1):6647. doi:10.1038/ s41598-018-25108-1

104. Kermanizadeh A, Jantzen K, Ward MB, et al. Nanomaterialinduced cell death in pulmonary and hepatic cells following exposure to three different metallic materials: the role of autophagy and apoptosis. Nanotoxicology. 2017;11(2):184-200. doi:10.1080/1743 5390.017.1279359

105. Lim Y, Kumar S. A single cut to pyroptosis. Oncotarget. 2015;6 (35):36926-36927. doi:10.18632/oncotarget.v6i35

106. Lei-Leston AC, Murphy AG, Maloy KJ. Epithelial cell inflammasomes in intestinal immunity and inflammation. Front Immunol. 2017;8:1168. doi:10.3389/fimmu.2017.01168

107. Shi J, Zhao Y, Wang K, et al. Cleavage of GSDMD by inflammatory caspases determines pyroptotic cell death. Nature. 2015;526 (7575):660-665. doi:10.1038/nature15514

108. Byrne BG, Dubuisson JF, Joshi AD, Persson JJ, Swanson MS. Inflammasome components coordinate autophagy and pyroptosis as macrophage responses to infection. Am Soc Microbiol. 2013;4 (1):e00620-e00612.

109. Bergsbaken T, Fink SL, Cookson BT. Pyroptosis: host cell death and inflammation. Nat Rev Microbiol. 2009;7(2):99-109. doi:10.1038/ nrmicro2070
110. Fink SL, Cookson BT. Caspase-1-dependent pore formation during pyroptosis leads to osmotic lysis of infected host macrophages. Cell Microbiol. 2006;8(11):1812-1825. doi:10.1111/cmi.2006.8.issue-11

111. Guo H, Xie M, Zhou C, Zheng M. The relevance of pyroptosis in the pathogenesis of liver diseases. Life Sci. 2019;223:69-73. doi:10.1016/j.lfs.2019.02.060

112. Man SM, Karki R, Kanneganti T-D. Molecular mechanisms and functions of pyroptosis, inflammatory caspases and inflammasomes in infectious diseases. Immunol Rev. 2017;277(1):61-75. doi:10.1111/imr.2017.277.issue-1

113. Kofahi HM, Taylor NGA, Hirasawa K, Grant MD, Russell RS. Hepatitis $\mathrm{C}$ virus infection of cultured human hepatoma cells causes apoptosis and pyroptosis in both infected and bystander cells. Sci Rep. 2016;6:37433. doi:10.1038/srep37433

114. Dumkova J, Smutna T, Vrlikova L, et al. Sub-chronic inhalation of lead oxide nanoparticles revealed their broad distribution and tissue-specific subcellular localization in target organs. Part Fibre Toxicol. 2017;14(1):55. doi:10.1186/s12989-017-0236-y

115. Xiao M, Chen W, Wang C, et al. Senescence and cell death in chronic liver injury: roles and mechanisms underlying hepatocarcinogenesis. Oncotarget. 2017;9(9):8772-8784. doi:10.18632/oncotarget.23622

116. Wu M-Y, Yiang G-T, Cheng P-W, Chu P-Y, Li C-J. Molecular targets in hepatocarcinogenesis and implications for therapy. $J$ Clin Med. 2018;7(8):213. doi:10.3390/jcm7080213
International Journal of Nanomedicine

\section{Publish your work in this journal}

The International Journal of Nanomedicine is an international, peerreviewed journal focusing on the application of nanotechnology in diagnostics, therapeutics, and drug delivery systems throughout the biomedical field. This journal is indexed on PubMed Central, MedLine, CAS, SciSearch ${ }^{\circledR}$, Current Contents ${ }^{\mathbb{R}} /$ Clinical Medicine, $^{-}$

\section{Dovepress}

Journal Citation Reports/Science Edition, EMBase, Scopus and the Elsevier Bibliographic databases. The manuscript management system is completely online and includes a very quick and fair peer-review system, which is all easy to use. Visit http://www.dovepress.com/ testimonials.php to read real quotes from published authors. 